CUPAUAM 24, 1997, pp. 159-188

\title{
APROXIMACIÓN AL DESARROLLO HISTÓRICO DEL NORTE DE LA PROVINCIA DE CORDOBA EN LA ANTIGÜEDAD: ANÁLISIS Y EVOLUCIÓN DEL POBLAMIENTO
}

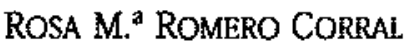

\section{Resumen}

Con este trabajo pretendenos hacer un análisis de la evolución histórica de la zona norte de la provincia de Cortoba, que abarca desde el Calcolítico hasta el tránsito a la Alta Edad Media.

Partiendo de las caracteristicas y posibilidades que ofrece el medio fisico, hemos estudiado el desarrollo del poblamiento en función de los condicionantes socioeconómicos y culturaies predominantes en cada periodo.

\section{Surnary}

With this paper, we introduce an analssys of the historical evolution in the north area of the province of Cordoba, that spread from Calcolithic period until the beginning of the Middles Ages.

Starting with the characteristics and possibjlities of the enviroment, we have studied the development of the population, according to predominants socieconomics and culturals condicionants on each period.

\section{INTRODUCCIÓN}

El norte de Córdoba reúne características particulares que la diferencian del resto de la provincia, proporcionándole una personalidad propia que se ha visto reflejada en su evolución histórica orientada, unas veces, hacia el Valle del Guadalquivir y, otras, hacia la Meseta y Extremadura en función de los condicionantes socioeconómicos que han predominado en cada periodo. 
Hasta el momento se han realizado algunos trabajos puntuales sobre períodos concretos (GAVILÂN, 1985; 1986 a: 1986 b; MURILLO, 1986 b; 1991, 1993; 1994 a), o estudios diacrónicos de algún término municipal (VAQuERIzo et alii, 1994) Sin embargo, quedaban algunos aspectos que apenas han sido tratados por la investigación arqueológica, así como yacimientos inéditos, algunos de ellos de cierta entidad. De ahí la oportunidad de plantearnos un estado de la cuestión sobre la evolución del poblamiento antiguo en el norte de la provincia de Córdoba, recogiendo lo ya realizado por otros investigadores $\mathrm{y}$, paralelamente, profundizando los aspectos que no han sido tratados con anterioridad.

La valoración de este sector como dependiente de los impulsos socioeconómicos y culturales del Valle del Guadalquivir ha dado lugar a su consideración como zona retardataria y de "segundo orden" con respecto a los cambios históricos sufridos en dicha zona, sin tener en cuenta que tiene unas características propias con impulsos procedentes también de otros sectores. Sin duda, esta idea sobre su evolución, sin ser del todo errónea, exige matizaciones, como veremos a continuación.

Metodológicamente hemos partido de una doble perspectiva en la que combinamos, por una parte, una aproximación a las diferencias regionales en función de los condicionamientos del medio físico y, por otra, un análisis cronológico a través de los cambios en el patrón de asentamiento como respuesta a los condicionantes históricos, socioeconómicos y culturales de cada momento. En definitiva, hemos considerado los recursos naturales como un factor más (aunque desde nuestro punto de vista de gran importancia) dentro de todo un sistema en el que los cambios en la tecnología, los sistemas de producción y las condiciones socioeconómicas son los elementos que generaron los cambios en el patrón de asentamiento y el paisaje cultural, con mayor o menor incidencia en función de la cantidad y tipos de recursos económicos.

En este sentido se pueden definir dos espacios bien singularizados desde el punto de vista geomorfológico, pero con algunas variantes dentro de cada uno de ellos, que han dado lugar a cuatro áreas ecológicas (Figura 1) con unos aprovechamientos agrícolas. ganaderos y mineros en cierto modo similares pero con caracteristicas propias. En dichos espacios el uso de la tierra está en estrecha interacción con los recursos con que cuenta cada zona, por lo que la diferenciación de los dominios ecológicos afecta también al propio patrón de asentamiento, no tanto por el tamaño como por la densidad y distribución de éstos.

\section{SÍNTESIS Y CARACTERIZACIÓN DEL TERRITORIO. EL MEDIO GEOGRÁFICO Y SUS POSIBILIDADES ECONÓMICAS}

Sierra Morena, entendiendo como tal el norte de las provincias de Jaén, Córdoba, Sevilla y Huelva, es un espacio de gran homogeneidad con entidad geográfica propia dentro de Andalucía. Supone una barrera fronteriza y zona de transición entre el Valle del Guadalquivir y la Meseta, aunque sus rasgos físicos la ponen en relación con Extre- 
madura y Castilla constituyendo una continuación de éstas en tierras andaluzas ${ }^{1}$. Se caracteriza por un medio físico desfavorable y baja densidad de población, lo que ha hecho de ella una zona económicamente marginal a lo largo de su historia.

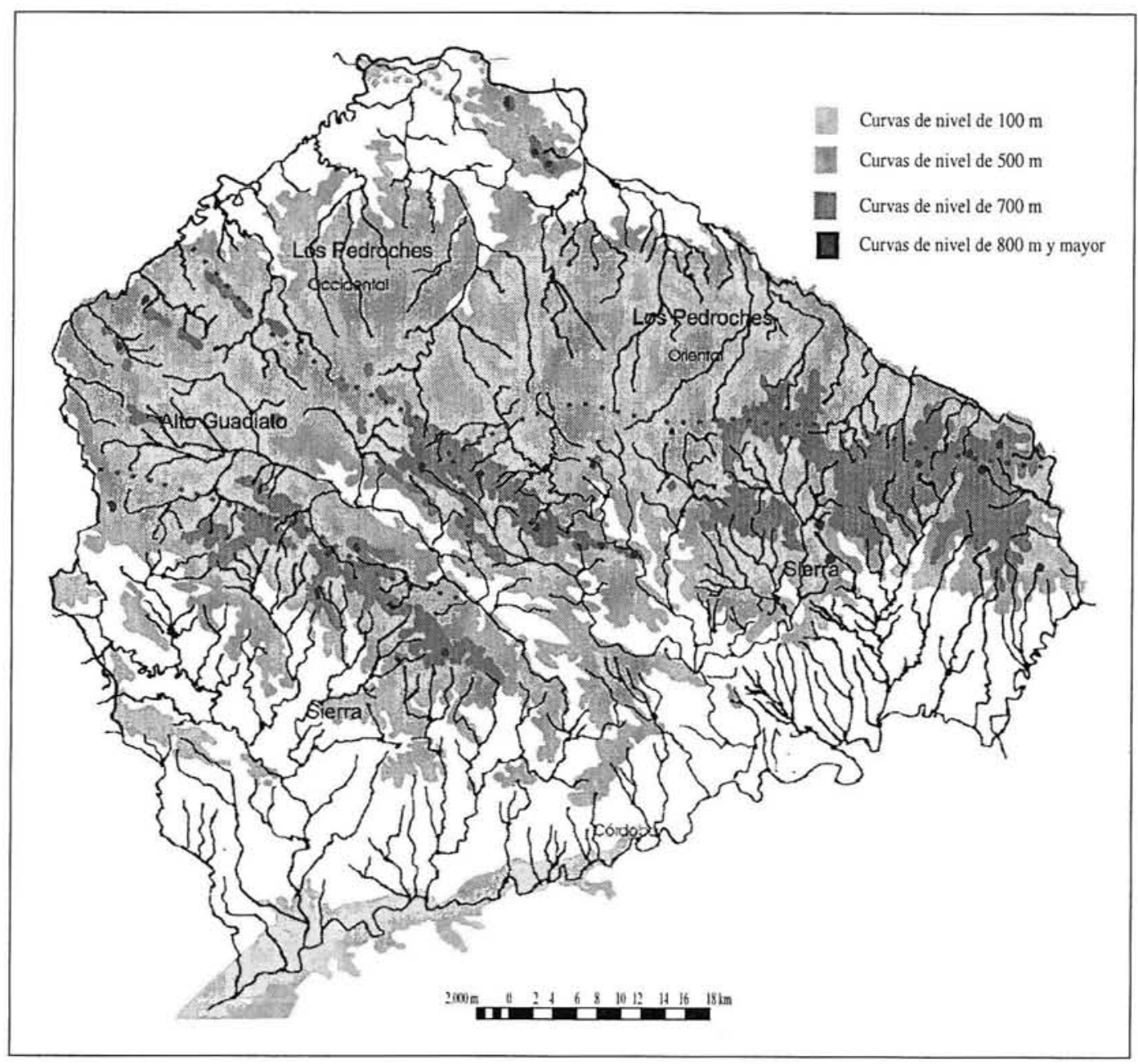

Figura 1.-Dominios ecológicos del norte de la provincia de Córdoba

Desde el punto de vista geofísico en la Sierra Morena cordobesa se encuentran los materiales más antiguos de la provincia, si bien dentro de este conjunto podemos diferenciar claramente dos zonas con características litológicas y de relieve distintas. La comarca de Los Pedroches encuadrada, geológicamente hablando, dentro de la Zona Cen-

${ }^{1}$ Una delimitación estrictamente geográfica de Sierra Morena tendría que incluir las comarcas de Monesterio y Azuaga en Badajoz y el Valle de Alcudia en Ciudad Real. 
tro Ibérica del Macizo Hespérico donde predomina el Paleozoico Superior, pertenece mayoritariamente a la cuenca hidrográfica del Guadiana; y, por otro lado, la Cuenca del Guadiato que forma parte de la Zona de Ossa Morena, con predominio del Precámbrico y Paleozoico Inferior, encuadrándose en su mayor parte dentro de la cuenca hidrográfica del Guadalquivir (LOPEZ-VALLE, 1993, 14-25).

La comarca de Los Pedroches está perfectamente individualizada con respecto al resto de Sierra Morena debido a la existencia de un macizo batolitico que se extiende, desde Extremadura, hasta parte de la provincia de Jaén. Tiene sentido noroeste-sureste y está encuadrada por los valles de los ríos Guadalmez y Cuzna.

El armazón se compone, principalmente, de granito aunque también hay otros elementos. Actualmente presenta un relieve bastante plano, accidentado sólo por suaves lomas, por lo que la mayor parte de la población se ha localizado en este sector de la comarca donde las tierras son más fértiles y el desarrollo de vías de comunicación no plantea problemas.

Dicha franja está delimitada al norte y al sur por dos anticlinales de naturaleza sedimentaria con un relieve algo más accidentado debido a su menor resistencia a la erosión. En ambos límites de la comarca afloran dos alineaciones montañosas constituidas por Cuarcitas Armoricanas, donde se localizan las mayores alturas de la comarca.

El Valle del Alto Guadiato se caracteriza por tener poco contraste en cuanto a la litología, lo que ha dado lugar a una escasa presencia de alineaciones montañosas de largo recorrido, y un relieve bastante plano. Está flanqueada por dos alineaciones más escarpadas y de mayor altura compuestas por materiales más duros que la comprimen. Esta zona ha actuado como eje de comunicación contando además con las tierras más aptas para el cultivo, por lo que la mayor parte del poblamiento se localiza en torno a la misma.

En ambas comarcas los ríos y afluentes tienen una acusada irregularidad estacional e interanual, ya que su régimen es pluviométrico y la zona se caracteriza por tener un clima continental extremado. con una desigual distribución de las precipitaciones e importantes contrastes climáticos en cuanto a la temperatura. Ello provoca grandes estiajes en los meses de verano, con caudales minimos que, en algunos casos, es prácticamente inexistente.

En lo que respecta a los recursos económicos que ofrece el medio físico debemos indicar que las características climáticas, topográficas y litológicas de la zona son poco favorables para la génesis de suelos bien desarrollados. De hecho, buena parte de esta zona carece de suelos en sentido estricto, entendiendo como tales los que muestran una clara diferenciación en horizontes. La tipología de aquellos es bastante reducida y se incluyen en la denominación general de tierras pardas meridionales (LOPEZ, 1985, 66.68) con diferencias internas en función del mayor o menor desarroilo en las formaciones edáficas. La agricultura ha sido y es muy limitada, con carácter de supervivencia o autoconsumo y con escasas posibilidades de generar excedentes que permitieran su comercialización.

Estas circunstancias naturales han contribuido al desarrollo de otras actividades económicas alternativas que debieron alcanzar igual o mayor importancia que la agricul- 
tura. Nos referimos a la ganadería y la actividad cinegética, favorecidas por la vegetación existente en la zona. Ciertamente, el norte de la provincia es el sector que presenta en la actualidad mayor riqueza florística natural, con un único tipo de vegetación potencial. La formación más típica es el bosque encinar, tradicionalmente adehesado (Lámina 1), caracterizada por un estrato arbóreo bien desarrollado que, en su fase madura, corresponde a un bosque esclerófilo. La etapa de garriga la constituyen coscojares, retamares, atochares y espartales. El segundo bosque en importancia es el del alcornoque que, junto con madroñales, actualmente, se conservan bastante bien.

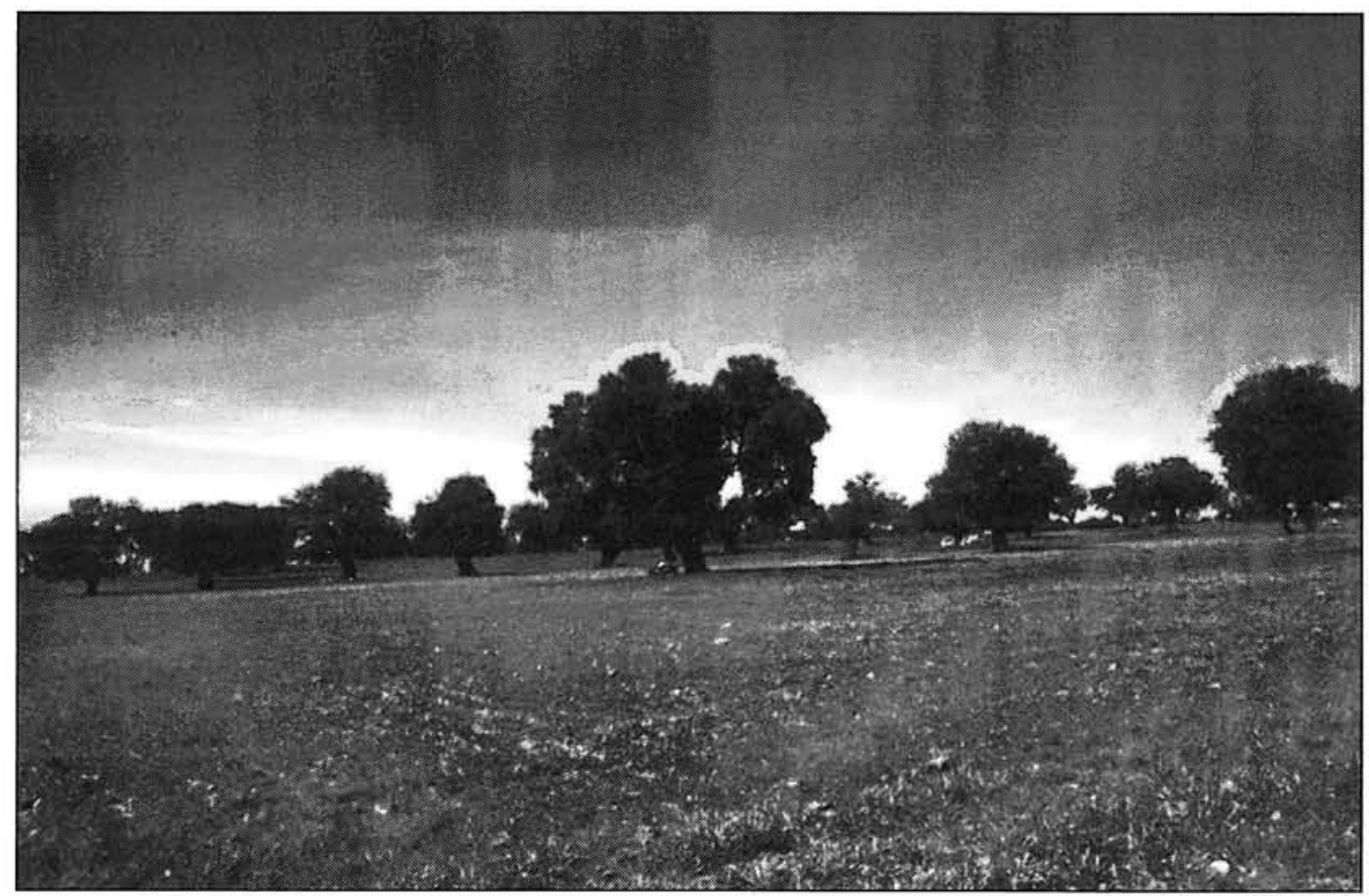

Lámina 1.-Paisaje característico de Los Pedroches: la dehesa

Como contrapartida, la zona norte de Córdoba, principalmente Los Pedroches y el Alto Guadiato, tienen una gran variedad y riqueza en yacimientos metalíferos que desde momentos muy antiguos, han sido explotados dando lugar a una floreciente minería, en la actualidad en franca decadencia. Los minerales que fueron explotados en la antigüedad pertenecen a yacimientos, a menudo, correspondientes a masas relativamente pequeñas, pero de leyes elevadas debido a los métodos rudimentarios de concentración y fundición utilizados. Las menas más abundantes en ambas comarcas son las de cobre y plomo; el oro acompaña minoritariamente a los minerales de cobre, mientras que la plata hace lo propio con los de plomo. Estos cuatro metales - cobre, plomo, plata y orohan sido tradicionalmente el principal atractivo minero de la zona y, en menor medida, el estaño. 
En lo que respecta a las posibilidades de comunicación que ofrece el medio físico, los recursos económicos y la topografía del terreno no favorecen un desarrollo de una amplia red viaria, tanto en época actual como en la antigüedad.

El principal obstáculo al trazado de las vías de comunicación ha sido y es la topografía abrupta, en especial en la zona de contacto con el Valle del Guadalquivir; por este motivo los caminos han transcurrido por puntos de paso obligado - vados y puertos de montaña- que se han mantenido prácticamente invariables a lo largo del tiempo.

Para el establecimiento de vías de comunicación hacia Los Pedroches se han utilizado historicamente una serie de collados y pasos naturales, tales como el Puerto del Calatraveño, o el Puerto de El Mochuelo (OCAÑA, 1970, 74-75). Los cursos fluviales de la zona suelen disponerse a lo largo de las sierras hasta encontrar una zona de debilidad en las mismas, como pueden ser las fallas, que permiten atravesarla generando gargantas utilizadas tradicionalmente como puntos de paso. Valgan como ejemplo el Guadalmez, que atraviesa la Sierra de Santa Eufemia, por el Castillo de Vioque; o el Valdeazogues, que atraviesa la Sierra Sur de Alcudia, por la Estación de Chillón. De igual modo hay que resaltar la importancia del Valle del Zújar (Lámina 2), un paso rápido y cómodo desde Córdoba hacia Extremadura y el Noroeste.

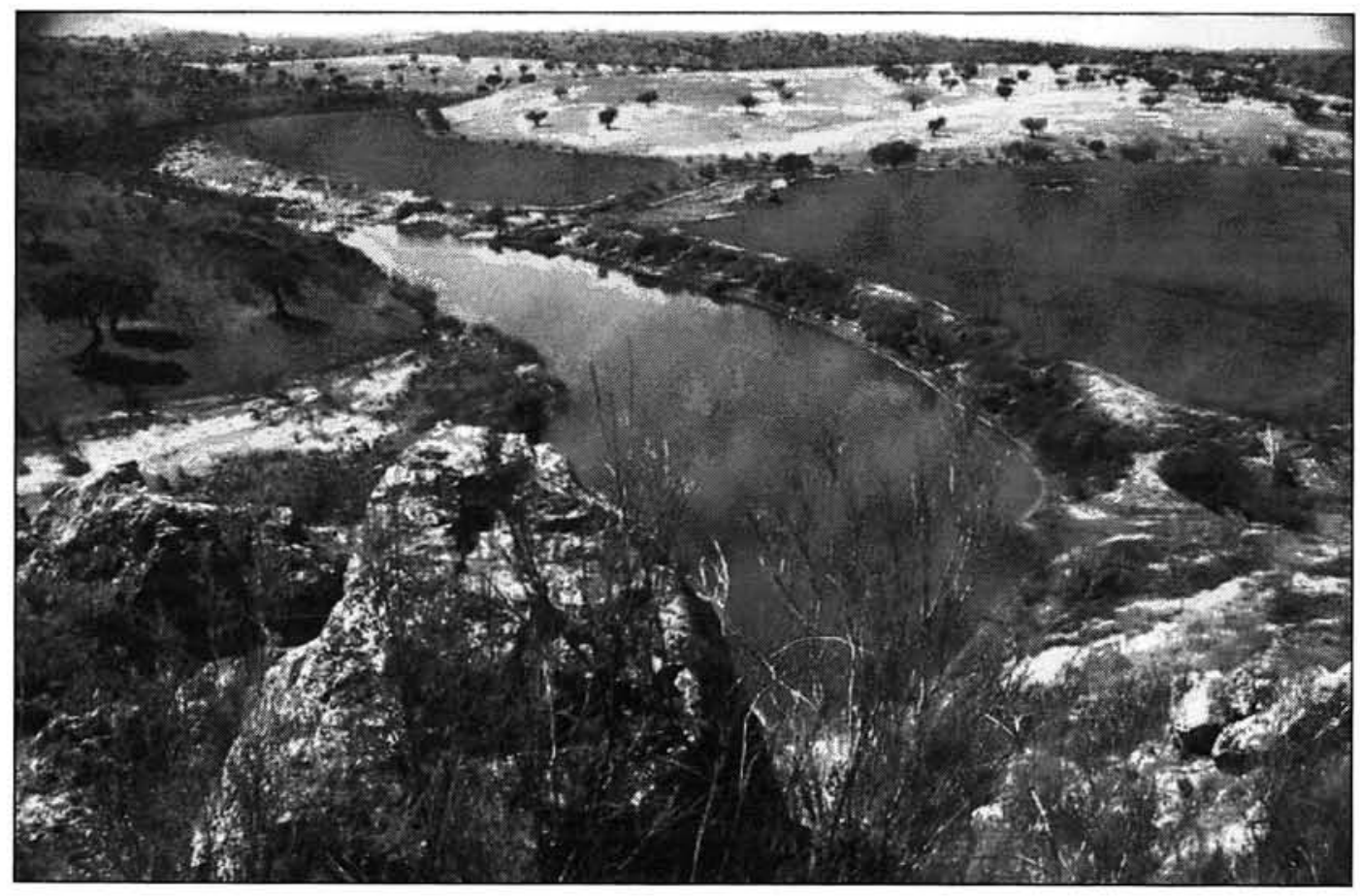

Lámina 2.-Río Zújar desde la Ermita de la Virgen de Alcantarilla (Belalcázar) 
La cuenca del Guadiato, con una topografia anormalmente suave si se compara con lo escarpado de las sierras vecinas, se convierte en la principal ruta de acceso hacia Sierra Morena.

Los ríos del sector suroriental están fuertemente encajados debido a la acción erosiva que, en ocasiones, ha dado lugar a gargantas que favorecen importantes vías de tránsito entre Sierra Morena con el Valle del Guadalquivir y el Valle de La Alcudia.

\section{ANÁLISIS DIACRÓNICO DEL POBLAMIENTO. APROXIMACIÓN AL DESARROLLO HISTORICO DEL NORTE DE LA PROVINCIA DE CORDOBA}

El medio físico, tanto por sus recursos económicos como por su geomorfologia, ha sido y es el principal condicionante del modelo de ocupación del sector norte de la provincia de Córdoba. Este hecho ha dado lugar a una distribución del poblamiento en torno a los dos ejes que estructuran el espacio: el Vaile del Guadiato y el sector central de Los Pedroches. En ambas zonas se localizan el mayor número de recursos naturales susceptibles de ser explotados, además de estar comunicados por las vías que históricamente, han enlazado con los centros cultural y económicamente más dinámicos (el Valle del Guadalquivir, la Meseta Sur y Extremadura) (cfr. MELCHOR, 1993; 1995; ZARZALEjOS, 1994).

Un análisis diacrónico del poblamiento debe iniciarse, según nuestro criterio, en el Calcolítico, primer momento en que se documenta un poblamiento mantenido, aunque con intensidad variable (cfr. GAVILÁN, 1985; 1986; GAVILÁN-VERA, 1989-90; VAQUERIZO et alii., 1994)

Este periodo ya ha sido analizado en numerosos trabajos (GAVLÁN, 1985; 1986 a; 1986 b. GAVILAN et alij, 1989; GAVILAN-VERA, 1989-90; MURILLO, 1986 a; 1986 b; MURILlo et alii., 1991). por lo que no vamos a entrar en él, aunque sí anotaremos algunas de sus características por cuanto interesa a nuestros objetivos.

Como ya hemos indicado, a partir del Calcolítico se produjo la primera ocupación que se mantuvo, de manera ininterrumpida, en el norte de la provincia de Córdoba. Se inició con un número, aún escaso, de pequeños asentamientos orientados a la colonización agraria (GAVILÁN-VERA, 1989-90, 150) en los sectores más productivos que fue aumentando en las fases siguientes, si bien con un cambio de orientación hacia lugares de mayores posibilidades estratégicas dentro de una dinámica generalizada en estos momentos por todo el área suroccidental (cfr. ENRíQUEZ, 1992, 268) Por otra parte, a partir de estos momentos comenzó a practicarse la mineria a pequeña escala aunque, en ningún caso fue el condicionante principal para la elección del asentamiento.

Se estableció, asi mismo, una incipiente red de comunicaciones (vid. VAQUERizo et alii, 1994, 90) en la que los pasos naturales que permiten la comunicación desde el Valle del Guadalquivir hacia la Meseta y Extremadura fueron pronto jalonados por asentamientos; son los casos de la Ermita de la Virgen de las Cruces (de gran relevancia para las comunicaciones con Ciudad Real y mantenido a lo largo del tiempo) y Santa Eufemia. Con cronología posterior, cerca de la zona de contacto entre Sierra Morena y el Valle del 
Guadalquivir y pasos naturales hacia Los Pedroches, estaría La Longuera, en la zona intermedia entre el Puerto del Calatraveño y los pasos hacia Ciudad Real.

El tránsito a la Edad del Bronce se muestra más difuso, como sucede en todo el suroeste de la Península. En lo que respecta al Vaile del Guadalquivir se ha propuesto una evolución a partir de contactos comerciales escasamente perceptibles en el registro arqueológico (cfr. MARTíN DE LA CRUZ, 1994, 116-118) En el sector norte de la provincia dicho proceso de cambio es más difícil de rastrear y las investigaciones realizadas no han permitido confirmar que se mantenga la misma dinámica que en las comunidades establecidas en el Valle del Guadalquivir Por otra parte, es probable que los materiales pertenecientes a las primeras fases de la Edad del Bronce no hayan sido debidamente consignados (lo que tampoco sería extraño debido a la falta de estratigrafias) y que, efectivamente, existiera un periodo de transición con una evolución más lenta debido a la situación periférica de nuestra zona de estudio como parecen apuntar algunos indicios (vid. VAQUERIZO et alii, 1994, 104), volviendo al ritmo de ocupación a partir del Bronce Final Orientalizante a causa del impacto colonizador y la demanda de metales. Desde luego no consideramos factible un vacío poblacional hasta el periodo orientalizante aunque, posiblemente, se produjo una considerable disminución en el número de lugares ocupados en beneficio de los más importantes sin llegar a un total despoblamiento.

El Bronce Final ha sido también, como el Calcoítico, un período bien estudiado en este sector dando lugar a una, relativamente, amplia y reciente bibliografía sobre el tema. Centrado en estudios de conjunto de la Cuenca Media del Guadalquivir y en la potencialidad minera del norte de la provincia (vid. MURILLO, 1993; 1994 a) han proporcionado nueva documentación en cuanto al desarrollo y cronología del Bronce Final en la zona. Por este motivo queremos tomar de estos datos sólo aquellos aspectos que resultan de interés para nuestro estudio.

El conjunto de asentamientos adscritos al Bronce Final en esta zona se insertaron en la denominada "área periférica tartésica" que se extiende hasta Ciudad Real (cfr. FERNANDEZ OCHOA-ZARZALEJOS, 1995). Ello significa su inclusión en la trama económica y comercial de Tartessos debido a la riqueza en metales y la existencia de vías de comunicación que enlazan el Valle del Guadalquivir (como eje articulador) con Extremadura y la Meseta. Ello dio lugar a una recuperación en la intensidad del poblamiento, así como la existencia de distintos tipos de asentamientos con funciones específicas basadas en la producción y comercialización de la plata, tal y como se ha podido documentar en otras áreas como Huelva (cfr. FeRnÁNDEZ, 1993, 414-415).

Dicha vinculación con el mundo tartesico se mantuvo hasta momentos muy avanzados del período orientalizante, al menos el siglo vi a.C., en el que se produjo un cambio en las estrategias de producción que anuncia el paso a la época túrdula y que adquiere comnotaciones diferentes en función de la localización geográfica. Igual que sucede en otros sectores del área periférica de Tartessos, la fuerte ligazón que se había mantenido con el Bajo Guadalquivir comenzó a disminuir de modo progresivo y cerraron su frontera optando por un modelo económico diferente, ajeno al que hasta entonces había sido el centro que se trasladó al Alto Guadalquivir. A partir de estos momentos 
comenzó a aparecer una creciente diferenciación social, así como la consolidación de formas complejas de integración política, lo que aparece reflejado en la ordenación del tertitorio.

La provincia de Cordoba no fue ajena a esta dinámica y el poblamiento se dispuso en función de una jerarquización basada en la funcionalidad económica de los asentamientos. Éstos se incluyeron dentro de una organización con un nivel urbano en la que el norte de la provincia de Córdoba estuvo en estrecha dependencia con los asentamientos situados a orllas del Guadalquivir, más importantes y de mayor tamaño, limitándose el papel de la Sierra a suministrar metales con una red de comunicaciones ya organizada (MuRillo, 1994 a, 455).

La integración de las zonas mineras en la periferia tartésica aceleró su proceso de aculturación mediante la circulación de artesanos e ideas y, al igual que parecen documentar los trabajos de campo realizados en Extremadura en los uiltimos años (RoDRfGUEZ, 1994, 111), o en la Meseta (FERNANDEZ OCHOA et alit, 1994, 145), hemos constatado para nuestra zona de estudio la fundación de hábitats estables que parecen responder a una particular estrategia de control del territorio sólo documentada en el sector donde, siglos después, se situó la Beturia túrdula.

Por otra parte la importante concentración de estelas de guerreros en el Valle del Zujar (cfr. MURilio, 1994 b, 11-32), a ambos lados del nio, y próximas a un vado y al asentamiento de Castillo de Madroñiz donde se sitúa una importante zona de paso hacia la Meseta desde Extremadura, parecen indicar que existió una clase de guerreros propia de las sociedades complejas y asociada a un fenómeno cultural en el que el control del territorio por dicha clase, y por tanto de las rutas, es predominante. Por este motivo su dispersión en esta zona indicaría la existencia de un control de dicho rio y los vados que permiten cruzarlo, ya que este sector pudo servir como zona de paso entre La Serena y Los Pedroches, asi como una ruta hacia el Valle de la Alcudia (cfr. ZARZALEjos, 1995, 127). Sin embargo, a diferencia de lo que opinan Ruiz-Gálvez y Galán $(1991,268)$, aunque también debió ser utilizado como zona de paso. pensamos que éste no sería el único camino por el que se pudo comunicar Extremadura con el Valle Medio del Guadaiquivir.

La presencia de las estelas indica, además, la estrecha vinculación en el desarrollo histórico del sector norte de la provincia de Córdoba con Extremadura y en mayor medida que con otros sectores periféricos como la Subbética o la Alta Andalucía.

El análisis del poblamiento en Extremadura documenta un conjunto de asentamientos de cronologia tardía para los que se ha planteado una hipótesis de lo más sugerente (RODRfGUEZ, 1994, 112-117; 1995 a, 218-219), intuida a través de la documentación obtenida en Cancho Roano. El patrón de asentamiento muestra la coexistencia de asentamientos orientalizantes en llano, o en laderas de pequeños cerros, y en altura con una distribución que define los mismos caminos seguidos por las estelas del suroeste. Respondian pues, a una planificación teritorial en la que predominaba el control de los abundantes recursos metalogénicos y agropecuarios, asi como de las principales rutas naturales por las que se comunicaba el Guadalquivir y la Meseta. 
La ocupación de los asentamientos en llano, o laderas de pequeños cerros, sin estructuras defensivas, documentados en Extremadura se situa cronológicamente en las fases finales del Periodo Orientalizante, al menos desde el siglo vi hasta el tránsito al siglo IV a.C., momento a partir del cual las elites de las áreas periféricas se consolidaron contribuyendo a una reafirmación aristocrática y optando por un modelo económico ajeno al centro, para adquirir, asi un papel de dinamizador económico. Los asentamientos en llano, tanto por su estructura interna como territorial, respondian a una fuerte influencia oriental también documentada en las necrópolis de este área (RODRtGUEZ-ENRt. QUE2, 1992, 532-536). Con diferente entidad, significación sociocultural y categoría económica tendrian no obstante, una funcionalidad similar a Cancho Roano y reunirian los intereses tartesios y fenicios en el interior. Actuarían como centros de mercado desde los que se distribuirían los productos y objetos autóctonos e importados (con un fuerte componente fenicio-púnico) a los asentamientos incluidos en su territorio concentrando. además, el poder económico, político y religioso.

La organización del territorio que predominó en el área de Extremadura se difun* dió hacia la Meseta y el sector norte de la provincia de Córdoba. La estructura de poblamiento en nuestra zona documenta una ocupación que estaba definida por la explotación de los recursos mineros y el control de las vías de comunicación coexistiendo, al igual que en Extremadura, asentamientos en altura y en liano, o en laderas de pequeños cerros, son los casos de La Atalayuela, Fuente de Los Tinajeros y Virgen de Alcantarilla.

De todos los asentamientos documentados en este periodo el mejor conocido es La Atalayuela, expoliado a mediados de los ochenta. Los materiales fueron estudiados en mayor profundidad por J. Murilio (VAQuerizo et alii. 1994, 108-111), quien les adjudica una cronología que abarca desde el siglo VI hasta mediados del siglo II a.C., en relación con materiales del Valle del Guadalquivir La falta de una estratigrafia que confirme la cronología propuesta para los mismos plantea ciertos problemas en la interpretación del asentamiento. Los materiales más modernos (posteriores a los siglos VI y $\vee$ a.C.) han sido fechados a partir de los documentados en otros asentamientos de la zona sur de la provincia de Córdoba. Sin embargo, ya hemos mencionado los estrechos vínculos que unen nuestra zona de estudio con el área extremeña y la Meseta, lo que puede verse en la evolución de los tipos de asentamientos, asi como su posterior pertenencia a la Beturia túrdula, momentos en los que se producen importantes contactos con la Meseta. Estos aspectos nos permiten sugerir un replanteamiento de la interpretación que preste mayor importancia a las posibles influencias procedentes de otros sectores para los materiales considerados más recientes.

En este sentido, para Rodríguez Diaz (1995 a, 219) los materiales más antiguos son muy similares a los que se han documentado en Cancho Roano, igual que su contexto. pues aparecen en una estancia construida con adobes y arruinada por un gran incendio. Por dicho motivo el asentamiento de La Atalayuela ha sido interpretado en la misma línea que los asentamientos en llano localizados en Extremadura. Este asentamiento, al igual que Cancho Roano y otros localizadios en el valle medio del Guadiana, deben ser 
entendidos como espacios de poder (político y religioso) al modo de células aristocráticas (cfr. RuIz, 1998,79).

Este modelo de ocupación del territorio finalizó, según los datos obtenidos en Medellín y Cancho Roano, en la transición del siglo $\mathrm{V}$ al $\mathrm{IV}$ a.C., con el abandono definitivo de los asentamientos en llano (RODRtGUEZ, 1994, 118-120). Pero, en el caso de La Atalayuela, si aceptamos la cronologia propuesta por J. Murillo (1993):, su ocupación continuaria hasta el siglo II a.C., si bien el momento de mayor auge parece fecharse entre el siglo VI y finales del siglo V a.C., coincidiendo con el último edificio de Cancho Roano.

A la luz de estos datos y si damos por válidos los planteamientos señalados, parece evidente que el sector donde posteriormente se localizará la Beturia se convirtió en estos momentos de tránsito, en el último reducto de un sistema socioeconómico ya agotado. que buscaba una recuperación económica en un nuevo modelo basado en el cambio de orientación hacia la producción agraria y el control de sus mercancías (CELESTINO. 1991, 191-192) Acometido en un momento crítico que coincide con la caída del comercio fenicio, la crisis de la minería en Andalucía Occidental y la reactivación de la periferia y del comercio griego.

Este proceso supuso el fin de una organización del territorio y la crisis de un sistema socioeconómico y cultural con efectos generalizados en el área tartésica y su periferia. Sin embargo, dicho período no debe ser considerado de decadencia, o recesión, como consideran algunos autores (BELEN-ESCACENA-BOZZINO, 1992, 72) sino, más bien aprovechados para una nueva organización que dio lugar a la Beturia túrdula. con lo que comenzó la recuperación y la integración de la zona hacia la órbita cartaginesa, en un fenomeno similar al ocurrido en todo el suroeste (BENDALA, 1992, 387).

Centrándonos en el poblamiento el proceso de consolidación de la Beturia en Extremadura se caracteriza por una ruptura con la fase anterior que puede observarse en varios aspectos. Por una parte, se inició una intensificación de las relaciones con la Meseta en el sector occidental, lo que desembocó en la "hispano-celtización" (BERROCAL, $1995,122)$ de la zona que daría lugar a la Beturia céltica; así como en un cambio en las estrategias del poblamiento que cristalizó en una cultura castreña, aunque también existían elementos de prestigio procedentes del mundo ibero-turdetano (ENRIQUEZ, 1995. 65). Por otra parte, en el sector oriental de la Beturia se intensificaron las relaciones con el valle del Guadalquivir, aunque tampoco faitaban elementos meseteños, lo que dio lugar al denominado período "túrdulo-turdetano" en el que nuevamente encontramos un cambio en la estructura de poblamiento, con una clara tendencia a ocupar enclaves destacados con gran valor estratégico y amplio dominio visual del entomo, o bien próximos a los principales vados o pasos del eje Guadiana-Guadalquivir (RoDRfGuEZ, 1995 a, 221222). También se ha documentado un importante desequilibrio en la ocupación global del territorio con una mayor concentración de asentamientos en los límites de éste, los valles del Züjar, Guadiana y Matachel.

En el norte de la provincia de Córdoba el panorama con respecto a los tipos de asentamientos se presenta mucho más difuso que en los sectores limítrofes, ya que conocemos muy pocos asentamientos con materiales encuadrables en este período. Son 
los situados en el Alto Guadiato (cfr. VAQUERIZO et alit, 1994,110), al sur de Hinojosa del Duque (VERA, 1996); los ya mencionados de La Atalayuela en Alcaracejos (VAQUERIZO et alii, 1994, 110): y, por último, los documentados en las excavaciones realizadas en el yacimiento de la Ermita de la Virgen de las Cruces (El Guijo), para el que se han constatado varias fases de ocupación, desde el Calcolítico Inicial hasta el siglo vil d.C, si bien la escasez de publicaciones sobre los resultados de la excavación y el poco interés prestado a la secuencia estratigráfica impide definir con claridad dichos periodos.

De todo el conjunto de materiales exhumados durante la excavación en ia Ermita de la Virgen de las Cruces hay una parte de cerámicas fabricadas a tomo, pertenecientes a un momento prerromano, fechable entre los siglos IV al Iii-iI a.C. En principio fueron considerados por sus excavadores como cerámicas celtibéricas (MARCos-VICENT, 1983. 32) aunque, en realidad, indican la existencia de un horizonte prerromano similar al existente en otras zonas de la Beturia con algunos elementos propiamente turdetanos.

Los escasos restos documentados en nuestro ámbito de estudio nos ponen en la línea de lo ya visto para el sector extremeño, en el que las áreas centrales muestran un acusado vacio poblacional y la presencia de una población caracterizada por la interacción de elementos meridionales y meseteños. Para el vacío poblacional se propone un pianteamiento que arranca del Periodo Orientalizante relacionado con la caida de Cancho Roano en torno al 400 a.C. y el surgimiento del destacado foco sociocultural emergente que es la Beturia céltica, hacia el que se desplazó la mayor parte de la población en busca de hierro (RodrfGuez, 1995 a, 223).

En este sentido, un factor de igual o mayor importancia que la explotación del plomo argentífero, y que contribuye a definir la entidad de la Beturia túrdula, debió radicar en el control y canalización de los contactos con el Guadalquivir y con el Levante (RODRfGLEZ, 1993, 253), aprovechando el camino natural que siglos después se convirtió en la vía Corduba-Emerita, destacado nudo de comunicaciones fluviales y terrestres hacia el sur y por la Meseta sur hacia Levante por Sisapo. De aquí queremos señalar la importancia del Zújar con el camino denominado "Ruta de los Santuarios" (cfr. MALUQUER, 1985, 22; 1989, 209). Dentro de este contexto puede explicarse la continuación de algunos asentamientos como La Estrella, importante punto de paso en el curso del Guadiato que comunica Extremadura con Córdoba; o La Atalayuela y Virgen de las Cruces, en la zona de paso que comunica Córdoba con la Meseta Sur a través del Calatraveño y el sector central de Los Pedroches.

A pesar de la escasez de documentación la zona norte de la provincia de Córdoba se muestra como un sector incluido dentro de la Beturia túrdula, vinculado en estos momentos más al desarrollo de Extremadura y la zona meseteña que al Valle del Guadalquivir. Por otra parte, estos aspectos coinciden con la idea de la Beturia que parece deducirse de los autores clásicos: un área alejada de los centros económicamente más dinámicos, poco poblada, y con una tardía romanización en el que entran en interacción relaciones culturales tanto con la Meseta como con la Alta Andalucía.

En otro orden de cosas hay que mencionar la existencia de varios testimonios que avalan la presencia de un componente púnico en el sector perteneciente a la Beturia túr- 
dula. En este sentido debemos tener en cuenta que la implantación cartaginesa en el Mediterráneo Occidental tuvo un fuerte componente de control territorial y, a partir de los Barca, si no antes, con una clara vocación de Estado. En este marco, la explotación de metales fue uno de los mayores intereses púnicos en la Península, centrándose en las zonas serranas del Alto Guadalquivir y del sureste, muy ricas en plata. La explotación minera debió ser muy intensa y, como Diodoro de Sicilia $(5,38,2)$ indica, todas las minas que explotaron los romanos lo habian sido antes por los cartagineses (BENDALA, 1987, 151-152)

Debido a la dispersión del numerario se ha pensado que sólo el espacio central de la Beturia túrdula estuvo ocupada por púnicos y los otros sectores por otras gentes (GARClA BELLIDO, 1995, 257-260), por lo que el norte de la provincia de Córdoba quedaría, según este planteamiento, fuera del área de poblamiento cartaginés. No obstante queremos señalar la gran proximidad geográfica que existe entre Arsa (GARCfA BELLIDO, 1993. 89-90) y Mellaria, aunque para esta última hasta la actualidad no se ha podido documentar una fundación anterior a la conquista romana (VAQUERizo et alii, 1994, 143). Por otra parte hay un gran número de minas de plomo argentifero cercanas a este asentamiento (la mejor conocida es La Loba), que fueron intensamente explotadas desde finales del siglo II a.C.

En otro orden de cosas, los topónimos de las ciudades aportan datos de interés sobre el origen étnico de los pobladores de la zona. En el caso de Baedro el nombre podria tener raigambre cartaginesa, aunque para algunos autores fue considerado céltico, como Bebryces (cfr. TOVAR, 1974-1976. 98) influidos, posiblemente, por su pertenencia a la Beturia. El nombre de Mellaria se considera romano (TOVAR, 1974-1976, 93), sin embargo existe otra ciudad en el área del Estrecho de Gibraltar con el mismo topónimo que podría estar relacionada con el mundo semita (ToVAR, 1974-1976, 68).

La posibilidad de una influencia púnica también en el norte de la provincia de Córdoba explicaría, en parte, la temprana ocupación y explotación minera de época romana, asi como la denominación de las ciudades romanas; sin embargo, hasta el momento, no contamos con testimonios concluyentes que permitan confirmar esta hipótesis.

Con la rápida conquista romana de la Beturia la zona norte de la provincia de Córdoba se convirtió en frontera-tapón entre el Valle del Guadalquivir y los territorios no conquistados entre el Tajo y el Guadiana (CORTJO, 1993, 66-67). Ello provocó un rápido control del territorio, de las vías de comunicación y de sus recursos económicos. Éste período comenzó manteniendo la misma tónica que en época prerromana, caracterizada ésta por su vacío poblacional. Sin embargo, desde finales del siglo II a.C. se intensificó la explotación de la riqueza minera, lo que aumentaria la ocupación del territorio hasta los siglos I y II d. C. La minería provocó, por tanto, el inicio del proceso de romanización; aunque la ubicación periférica con respecto a los grandes ejes de comunicación siempre determinó una presencia romana más escasa y, por tanto, un proceso de aculturación más lento que en otras áreas.

Con la presencia romana en la zona se impuso un nuevo modo de vida que se tradujo en un cambio en la ordenación del territorio. Los escasos asentamientos prerromanos que pueden localizarse hoy en la zona son muy dispersos, con poblados en al- 
tura, situados estratégicamente en función de las vías de comunicación, a excepción de La Atalayuela. Roma actuó sobre esta estructura con la fundación de nuevas ciudades, tal sería el caso de Mellaria; o aprovechando la funcionalidad y lugar de asentamientos de otros ya existentes, caso Solia (vid. BENDALA et alii, 1986, 128). Introdujo una nueva organización social y económica que modificó el paisaje cultural que dejaría sentir sus efectos a partir de época imperial, especialmente a partir de la concesión del ius Latii en época flavia y la creación de municipios intimamente ligados a los asentamientos rurales con los que formaba una unidad, tanto política como económica y social.

No obstante, este proceso de romanización se produjo de forma lenta con una reorganización territorial y económica que dió plenos resultados entrado ya el siglo I d.C., homogeneizándose con el resto del territorio bético. En dicho proceso los oppida citados por Plinio para la Beturia túrdula adquirieron un papel predominante, y dirigirian, en gran medida, la adaptación del territorio a aquella nueva situación.

A tenor de los datos aportados por C. Domergue (1985, 1987; 1989) y Blázquez (1981; 1982-83) y por lo que conocemos en otras zonas mineras de Sierra Morena, como Castulo, parece que las minas del norte de Córdoba no empezaron a explotarse hasta el final de las guerras lusitanas debido, en gran medida, a la inestabilidad que existía hasta entonces, por tanto, su beneficio a gran escala no comenzaría antes de finales del siglo II a.C., siendo la primera mitad del siglo I a.C. el periodo de mayor actividad. A partir del cambio de Era comenzó su decadencia (DOMERGUE, 1990, 191) debido a varios motivos ya apuntados por otros autores (cfr. DOMERGUE, 1972, 616; VAQUERIZO et alii, 1994, 120121). Posteriormente se produjo cierta recuperación en la actividad minera debido a la política económica llevada a cabo durante el Alto Imperio y en la que se planteó una racionalización y sistematización de las explotaciones, no obstante siempre se mantuvo el centro de Cerro Muriano debido a su gran productividad.

El mineral más explotado fue el plomo argentifero, dada la alta cantidad de plata que contenía y, ya en menor proporción de cobre. Una de las consecuencias más importantes fue la aparición de numerosos núcleos de población junto a las minas que servirian como lugares de habitación y almacenamiento. Algunas de estas contaban con fundiciones anexas donde se realizaba el primer tratamiento del mineral que, en otros casos, aparecian aisladas si bien relativamente próximas a alguna mina. Estos asentamientos sólo fueron ocupados durante el periodo de explotación, pero dieron lugar a circuitos comerciales que no habian existido hasta entonces. Un ejemplo sería el derecho de paso de la Societas Sisaponensis para llevar el mineral hasta Corduba (VENTURA, 1993). A esto tenemos que aña dir el comercio de productos básicos para los habitantes de la zona.

Es. por todo lo expuesto, el que el poblamiento del norte de Córdoba en época republicana estuviera estrechamente relacionado con la explotación de las minas. En lo que respecta a otros tipos de asentamientos de mayor envergadura, cuya funcionalidad no fue estrictamente minera, pocos son los datos con los que contamos. Si bien es cierto que, incluso en época imperial, este sector se caracterizó por su baja densidad de poblamiento parece indudable que para la organización de la actividad minera serian necesarios otro tipo de asentamientos de carácter administrativo que facilitaran la explota- 
ción del territorio más próximos a la propia Corduba. Así sucede en la cuenca noroccidental del Duero, con un importante potencial minero y escasa jerarquización, tanto desde el punto de vista social como poblacional (OREJAS, 1996, 174).

En el caso que nos ocupa serían tres los núcleos urbanos encargados de organizar el amplio territorio que hoy engloba el norte de la provincia de Córdoba (Figura 2), aunque no se sabe, con exactitud, cual pudo ser su origen. Dos de ellos - Solia y Baedrose localizan en la comarca de Los Pedroches, en la zona occidental y oriental, respectivamente, sirvieron como centros organizativos de un espacio de gran amplitud que englobaba dicha comarca y una pequeña parte de la de Ciudad Real. El tercer núcleo urbano - Mellaria - constituía el único de la zona del Alto Guadiato.

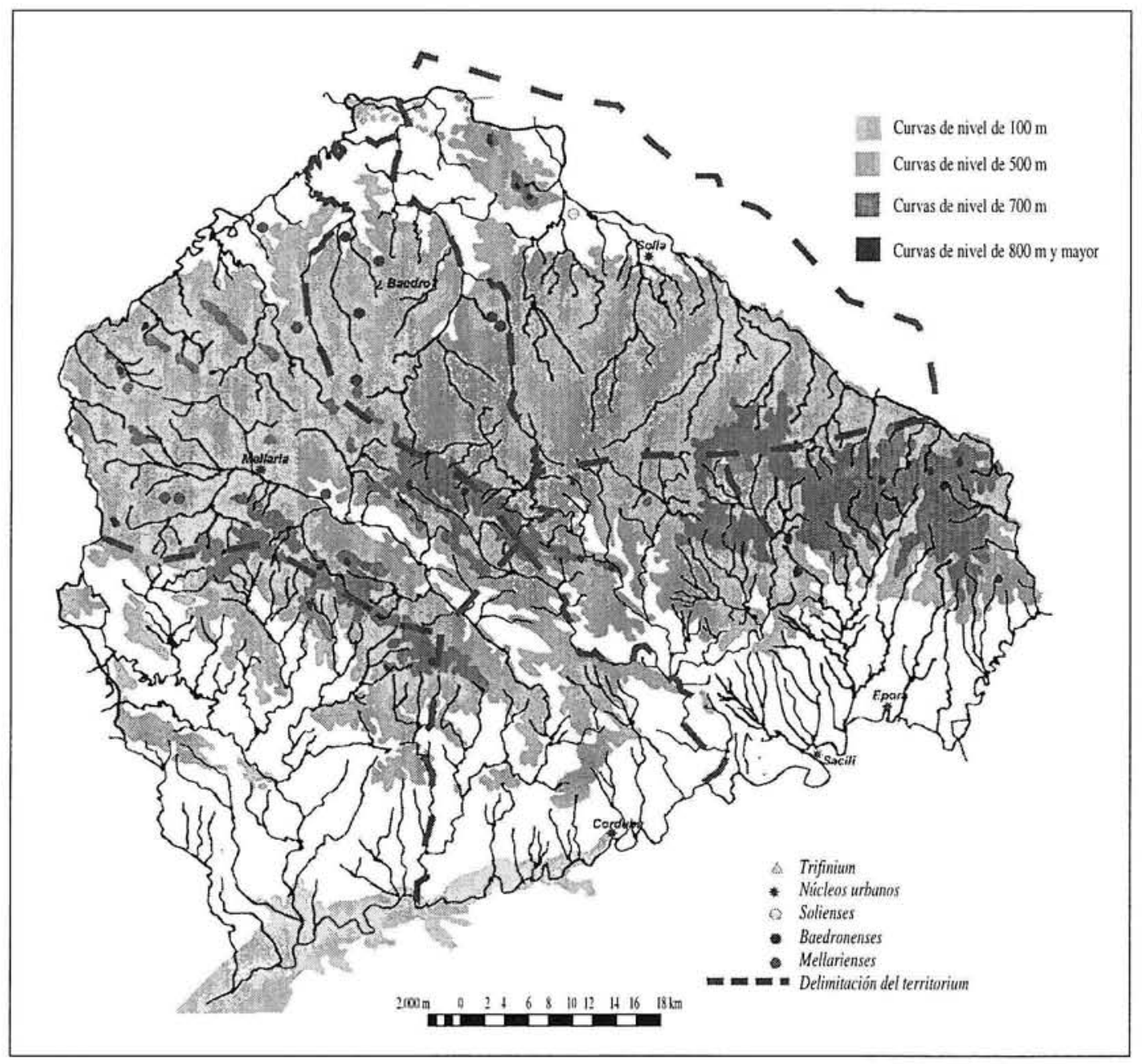

Figura 2.-Distribución de los epigrafes que hacen mención a la origo y delimitación del territorrium de cada ciudad 
Mellaria se ubicó en el Cerro de Masatrigo (Fuente Obejuna). Plinio lo cita como un oppidum perteneciente a la Beturia túrdula, lo que implicaria un origen prerromano, si bien los datos con que contamos en la actualidad no apuntan a esta posibilidad. Por el momento sabemos que su origen no fue anterior a época republicana (VAQUERIzO et alii, 1994, 143) y, ya desde aquel momento, debió servir como centro vital en el control y romanización de la zona a causa de su ubicación estratégica de cara a las comunicaciones con Extremadura, y organización y explotación de las minas de aquei territorio. En lo que concierne a su abandono los materiales de superficie indican una cronología hasta el siglo ill d.C., si bien la numismática recogida en la zona indica una ocupación ininterrumpida, desde época altoimperial hasta el siglo $v$ d.C. (VAQUERIZO et alii, 1994, 153). En época flavia, y dentro de la política de municipalización llevada a cabo en este periodo, alcanzó el estatuto de ciudad privilegiada como municipium, lo que corroboran numerosos epígrafes.

La ciudad de Baedro aparece mencionada en la obra de Plinio (Nat. Hist. III 3. 10) con grafía errónea (Baebro), al sur del río Guadalquivir y fuera, por tanto, del territorio perteneciente a la Beturia túrdula. No obstante pensamos que su localización en el sector occidental de Los Pedroches está fuera de dudas gracias a los hallazgos de inscripciones funerarias que mencionan la origo (STYLOW, 1985, 661). Sin embargo, actualmente, no conocemos la ubicación exacta de la ciudad ya que entre los yacimientos de época romana conocidos en este sector ninguno puede relacionarse con un asentamiento urbano de semejante entidad: no obstante, se han propuesto diferentes hipótesis ninguna de ellas definitiva. Algunos autores han planteado la posibilidad de su ubicación en $\mathrm{El}$ Viso (ICLESIAS, 1977) basándose en los epigrafes localizados y en el único que menciona el ordo baedronensis (CIL II, 7,845); otros, en cambio, defienden la ubicación del núcleo urbano entre Hinojosa del Duque y Belalcázar (STYLOW, 1991, 18).

Para nosotros la localización propuesta por Stylow es la más acertada. Por una parte el poblamiento rural, tradicionalmente, se disponía de manera habitual próximo a las ciudades y a escasa distancia de las principales vías de comunicación y, en esta zona, los asentamientos conocidos hasta la fecha están concentrados en las proximidades de Hinojosa del Duque y Belalcózar. Además, entre ambos pasa una vía que se corresponde, en gran parte, con la Vereda de El Viso. Está jalonada por varios asentamientos y enlaza las vías Corduba-Emerita y Corduba-Sisapo, cruzando el sector central de Los Pedroches por Belalcázar y cerca de Hinojosa del Duque (Figura 3)

Es posible que Baedro existiera ya en época republicana para administrar y organizar las numerosas minas existentes en este sector, pues conocemos una societas con las siglas SBA documentadas en la mina Santa Bárbara, y que se ha relacionado, entre otras posibilidades, con la Societas Baedronensis (RoDRIGUEZ, 1988, 383). Lo que está fuera de dudas es que adquirió el status de municipium iuris latini en época flavia, contando con numerosa documentación epigráfica.

Con respecto a Solia su nombre no aparece mencionado en las fuentes clásicas, pero la conocemos gracias al hallazgo del trifinium de Villanueva de Córdoba donde aparece mencionado el topónimo. Actualmente parece aceptada la ubicación de la ciu- 


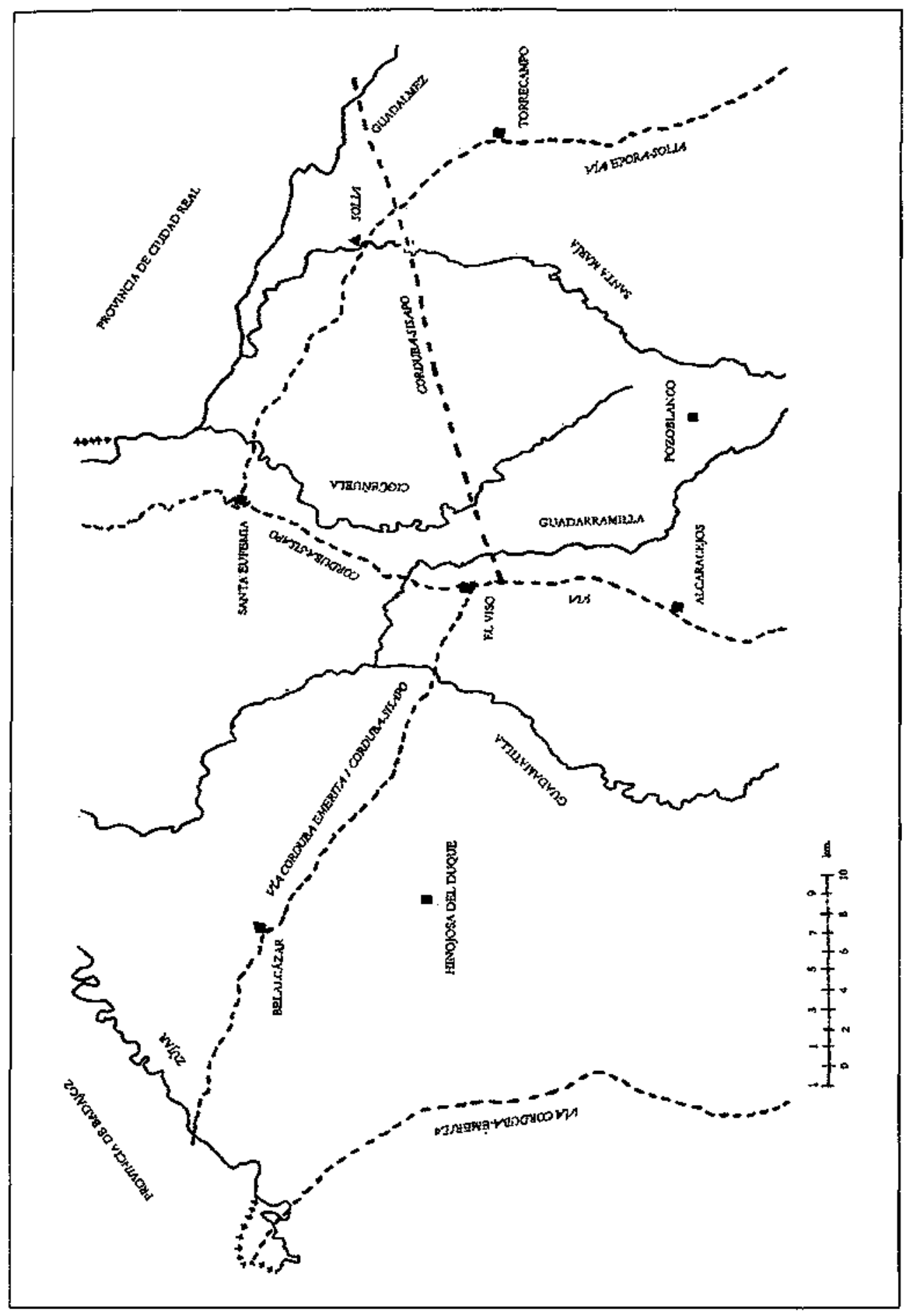

款

175 
dad en Majadaiglesia, a poca distancia al norte de la Ermita de la Virgen de las Cruces, en el término municipal de El Guijo. Se situaba sobre un cerro amesetado (Lámina 3) en el que todavía hoy se pueden observar numerosos restos romanos en varios sectores que, ya en su día, fueron indicados por Ramírez de las Casas-Deza $(1986,81)$ y excavados a principios de siglo (cfr. OCAÑA, 1962, 124). En los años 80 se realizaron nuevos trabajos de campo, donde se sitúa la Ermita, motivadas por la existencia de una pila bautismal paleocristiana en la sacristía de la misma (MARCOS-VICENT, 1983).

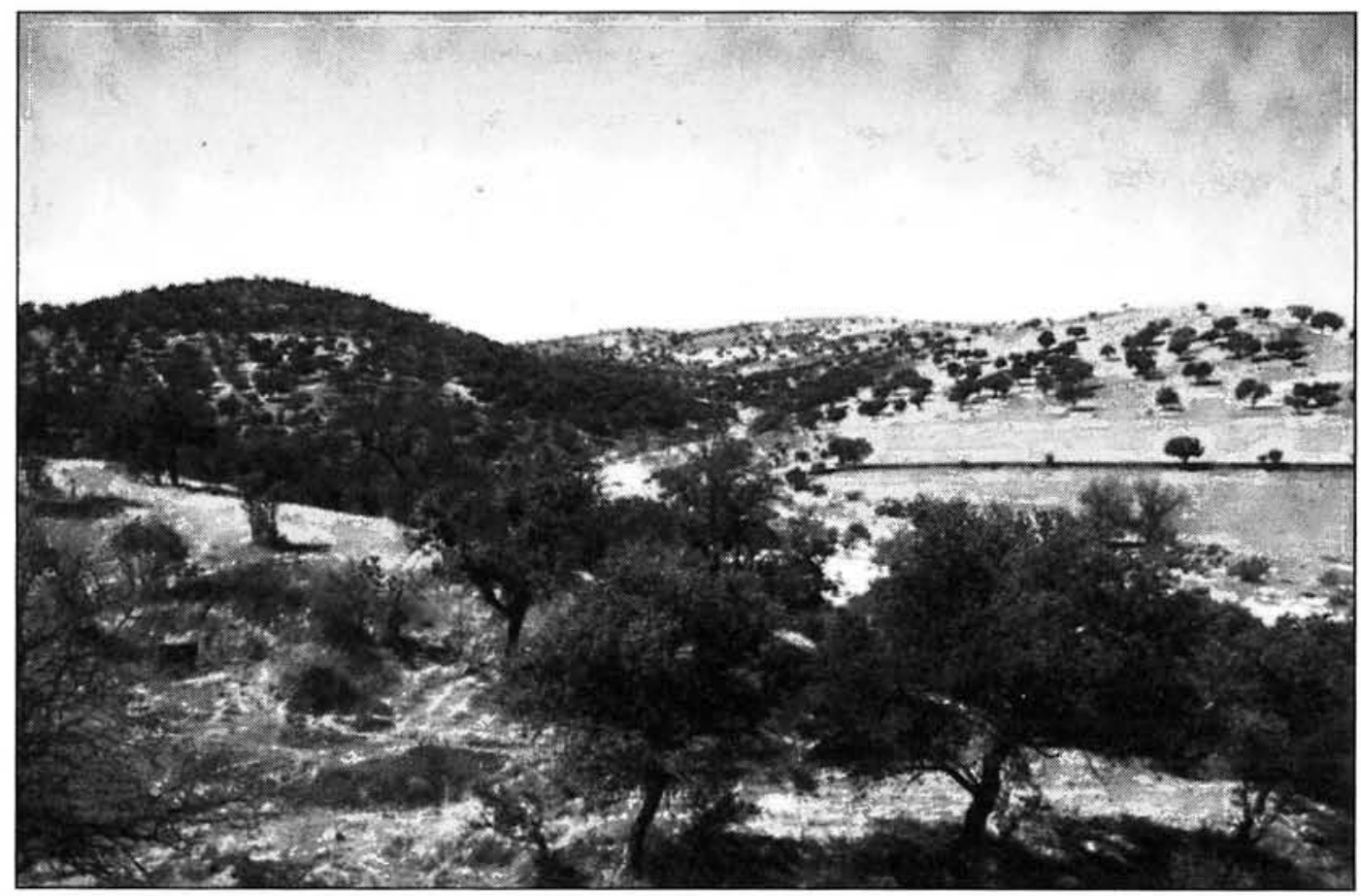

Lámina 3. - Vista desde el Cerro de Majadaiglesia (Solia)

El yacimiento cuenta con una muralla adaptada a la topografía del terreno de la que aún se conserva en algunos tramos y una torre en el extremo sureste. En la ladera sur hay un conjunto de construcciones hidráulicas, fabricadas en opus caementicium con revestimiento de opus signinum; un frogón de opus caementicium (Lámina 4) con ladrillos y restos de pavimento y, por último, un canal con el arranque de una bóveda, aunque no conservado en la actualidad. En la parte superior de la meseta se localizan dos construcciones subterráneas de gran tamaño. En el Museo Arqueológico de Córdoba se conserva un relieve con deidades de carácter eleusiano que pudo pertenecer al basamento de una estatua encontrado a principios del presente siglo en las proximidades de Majadaiglesia. 
También en esta zona han aparecido numerosos epígrafes funerarios que constatan la existencia de una importante necrópolis con una cronología que abarca desde la primera mitad del siglo I d.C. hasta el siglo VII, si bien no conocemos enterramientos de la segunda mitad del siglo III, ni del siglo IV d.C.

La cronología de estos restos romanos testimonian una ocupación continuada del asentamiento descle, al menos, la primera mitad del siglo I d.C. hasta el siglo VII d. C. Pero, probablemente, ya desde la fase túrdula existió una ocupación de cierta importancia debido, tanto a su ubicación geográfica en el camino de Sisapo a Corduba, como centro de una zona económicamente vinculada a la ganadería. En ello apoyamos nuestra defensa de también una ocupación en época republicana, aunque en la actualidad todavía no se hayan encontrado materiales arqueológicos que lo confirmen.

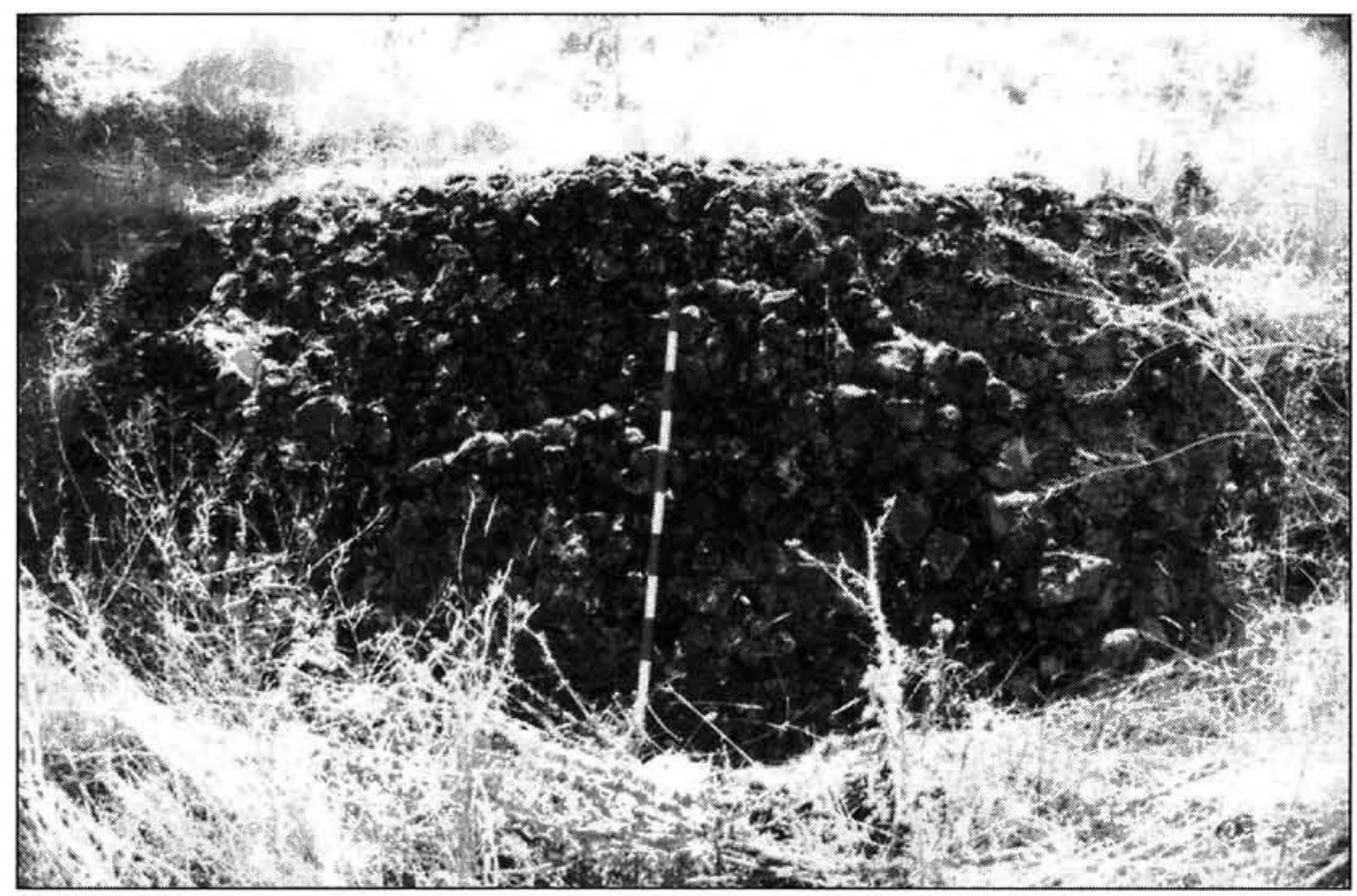

Lámina 4.-Frogón de opus caementicium del Cerro de Majadaigleia (Solia)

No se sabe con exactitud el status jurídico de este núcleo urbano, pero bien podría ser un municipio de época flavia, al igual que el resto de los núcleos urbanos de la zona norte de la provincia de Córdoba. No se conoce ninguna mención al ordo ni a la tribu, pero sabemos que un presbítero de Solia tomó parte en el Concilio de Elvira. Celebrado éste entre el 300 y 313, ello parece indicar que la ciudad alcanzó el citado rango de municipio (STYLOw, 1991, 18). A esto podemos añadir los datos conocidos para Baedro y Mellaria, municipia iuris latini en época flavia y que nos hace pensar un similar desarrollo para Solia. 
Dentro de la nueva ordenación imperial las vías de comunicación y, especialmente, las ciudades se convirtieron en los principales ejes vertebradores del territorio. Todos los oppida mencionados por Plinio en la Beturia Túrdula alcanzaron el rango de municipio en época flavia. Asi, el sector centro y norte del Conventus Cordubensis, se dibuja como una región homogénea, tanto en el terreno político como en el económico (STYLOW, 1991, 25).

Pero dentro de este proceso de cambio de las estructuras políticas, económicas y sociales, también el paisaje rural cambió sustancialmente. De un poblamiento agrupado en torno a escasos y pequeños núcleos, se pasó a otro que pronto acabaría por controlar la explotación de los fundi asignados tras la parcelación colonial desde centros de explotación agrícola. La aparición del poblamiento rural coincidió con la adquisición del status de municipium de las ciudades y el reparto colonial del territorio. Por tanto, a partir de mediados del siglo I d.C. comenzó una auténtica colonización del espacio motivada por el cambio en las condiciones socioeconómicas que tuvo como consecuencia un nuevo modelo de uso de la tierra y un cambio en el paisaje cultural.

Los asentamientos rurales fueron fundaciones ex novo y estuvieron orientadas a la puesta en valor de tierras hasta entonces apenas explotadas caso, por ejemplo, del sector centro-occidental de Los Pedroches. Esta revalorización agraria implicó un aumento de la población y la ocupación rural con respecto a momentos anteriores, tal y como indican la abundancia y dispersión de los asentamientos. El sector oriental, sin embargo, debió quedar más orientado hacia la explotación ganadera dado que la escasa productividad de la tierra para la explotación agrícola no requería de muchos asentamientos tipo villa.

Es, por tanto, desde mediados-finales del siglo I d.C. y durante el siglo II d.C. cuando se produjo el periodo de expansión y consolidación del poblamiento rural con una mayor concentración a lo largo del siglo il d.C., al igual que sucedió en todo el conjunto de la Bética (PADLla, 1989, 53). A partir de aquel momento, se produjo un cambio de mentalidad con un progresivo deterioro de los elementos tradicionales en que se fundaba la prosperidad de las ciudades de los primeros siglos del Imperio, tales como el evergetismo y la acción de las curias (ARCE, 1982, 85-86). y para los que no tenemos datos a partir del siglo ill. Esta situación no impidió que durante los siglos III, IV y $\vee$ d.C. las ciudades continuaran manteniendo una vida activa como centros económicos y de relaciones sociales dentro de un ámbito regional e interprovincial. Se mantuvo en Mellaria y en Solia, y lo mismo podemos pensar para Baedro a tenor de los datos proporcionados por el poblamiento nural adscrito al territorium de la ciudad.

Asi mismo, se mantuvo estable la unidad ciudad-campo aunque progresivamente, el segundo elemento fue dominado y ordenado por el primero. Aunque algunos asentamientos parece que fueron abandonados a lo largo de aquel siglo son la excepción, pues la proporción es más baja que en otras zonas de la provincia (cfr. CARRILLO-HIDALGO, 1990: CARRILLO, 1991). Los asentamientos que continuaron ocupados en los siglos IV y V d.C. y, probablemente también durante el siglo III d.C. descendieron en número, lo cual debe ponerse en relación con el cambio en las condiciones políticas y socioeconómicas 
y, consecuentemente, con el tipo de producción agrícola y uso de la tierra en el que se consolidó el proceso de concentración de grandes propiedades (ARCE, 1982, 85-86).

La localización de los asentamientos coincide con las prescripciones que señalan los agrónomos latinos en cuanto a distancias de las vías principales de comunicación; proximidad a los núcleos urbanos; ubicación topográfica en laderas, a media altura, en pequeñas lomas o en llanuras; con agua en las cercanías, cuyo caso más paradigmático es la presa de Torretejada (ROMEro, 1995) (Lámina 5); y, por último, próximos a terrenos fértiles, dado el carácter agrícola de los asentamientos, por lo que la mayor densidad de poblamiento hay que situarlo en las zonas más productivas sin embargo, dada la escasez de éstas en nuestra zona la concentración de poblamiento se dio sólo en sectores muy limitados. En algunos casos se daría una economía diversificada por la proximidad a las zonas de sierra y bosques que hay que relacionar con una economía de tipo mixto, en la que la ganadería y la caza jugarían un papel de similar relevancia a la agricultura.

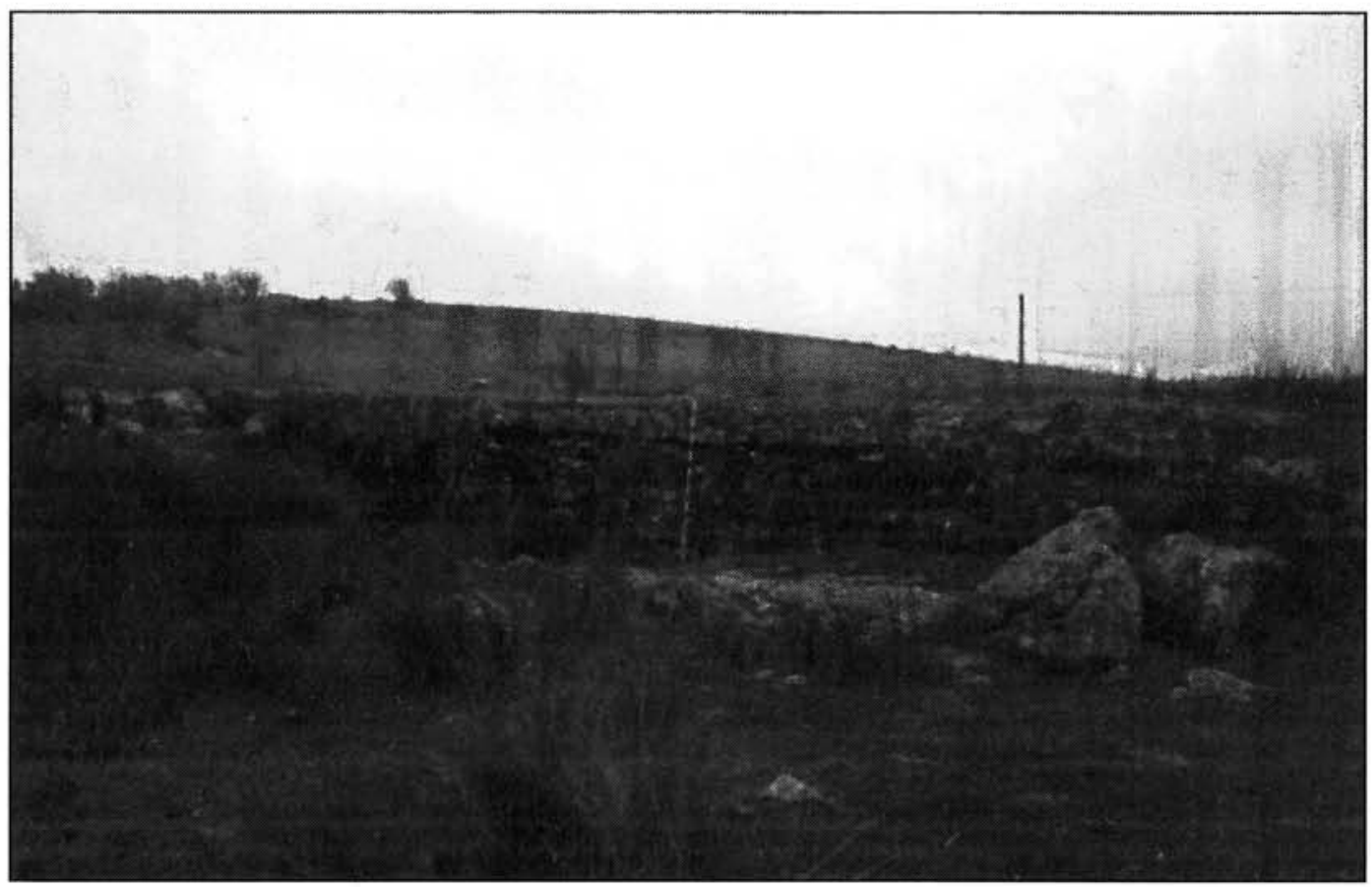

Lámina 5.-Presa de Torretejada (Belalcázar) descle cara de aguas abajo

Con los datos que contamos y siempre teniendo en cuenta que pueden existir más asentamientos para los que no contamos con información, podemos decir que el patrón de asentamiento es poco uniforme, con una baja densidad de poblamiento que se mantuvo bastante estable en número a lo largo de los siglos; dispuesto en función de los recursos, por lo que el mayor número de ellos se localizan en determinadas zonas, mientras que en otras, hasta la fecha está prácticamente vacía de yacimientos y la epigrafía es 
muy escasa. La irrigación, como en el caso de Torretejada, aumentaría obviamente la productividad, aunque estos sistemas no llegarian a paliar del todo el problema de unas tierras escasamente fértiles.

Los factores que condicionaron el poblamiento durante el tránsito a la Alta Edad Media estuvieron fuertemente influidos por la situación política y el papel jugado por la Iglesia. A grandes rasgos se produjo un cambio en el patrón de asentamiento con respecto a momentos anteriores, cambio que parece relacionarse más con el gobierno visigodo que con el colapso del Imperio Romano (CARR, 1992, 171) No obstante, estas modificaciones son escasamente perceptibles y sólo apreciables en el descenso del número de asentamientos, la proliferación de las necrópolis y la "cristianización" del paisaje.

Durante los siglos VI y VII, las ciudades de la zona meridional de la Península que habían sobrevivido a la crisis pasaron a desempeñar un importante papel conservando antiguas funciones y, paralelamente, adoptando otras nuevas (SALVADOR, 1990, 78) En lo que se refiere a los núcleos urbanos de nuestra zona de estudio sólo Solia continuó ocupada, al menos hasta el siglo VII d.C., como indican los epigrafes funerarios de la Ermita de la Virgen de las Cruces (CIL II2, 7.764, 7,765) y la existencia de un baptisterio cuadrilobulado con escalera de ingreso perteneciente a una basílica paleocristiana situada junto a la necrópolis (MARCOS-VICENT, 1983, 31) Aunque no pensamos que llegara a adquirir un papel muy relevante cosa que, por otra parte, nunca había tenido, nuevamente su situación geográfica en una zona de control de comunicaciones hacia la Meseta Sur favoreció su continuidad.

En lo que respecta al mundo rural ningura de las grandes explotaciones documentadas en época romana parece que continuara. No obstante, es posible que existieran pequeñas aideas independientes dedicadas a la agricultura, tal y como parecen documentar los materiales visigodos localizados en El Hoyo y el Penón del Cuervo, en el término municipal de Fuente Obejuna (SALVADOR, 1990, 265-278) Un importante número de población debió dedicarse a la práctica de una ganadería itinerante que explotaría los pastos comunitarios, tal y como parecen indicar el gran número de tumbas antropoídes distribuidas por esta zona (Lámina 6).

Como ya hemos indicado, el papel jugado por la Iglesia introdujo un nuevo elemento en la ocupación del territorio. Contamos con centros de culto que parecen corresponder a núcleos aglutinadores de asentamientos de pequeño tamaño, caso de la Ermita de San Bartolomé, en el término municipal de Fuente Obejuna, que estaría relacionado con los asentamientos de El Hoyo y Peñón del Cuervo. Un ejemplo diferente sería la Basilica de El Germo, en el término municipal de Espiel, probablemente un monasterio (SALVADOR, 1990, 218) con carácter de latifundio como tantos otros que se fueron multiplicando en aquellos siglos como salida a la precaria forma de vida existente.

La distribución del poblamiento en aquellos momentos se muestra, por tanto, muy disperso aunque a juzgar por los restos documentados debió ser relativamente abundante. En la mayor parte de los casos seria de carácter itinerante asociado, fundamentalmente, con la actividad ganadera, aunque está documentada la existencia de una gran propiedad, la única hasta el momento. en El Germo. De tipo religioso tendría, no obstante, las mismas características en su funcionamiento que las laicas. 


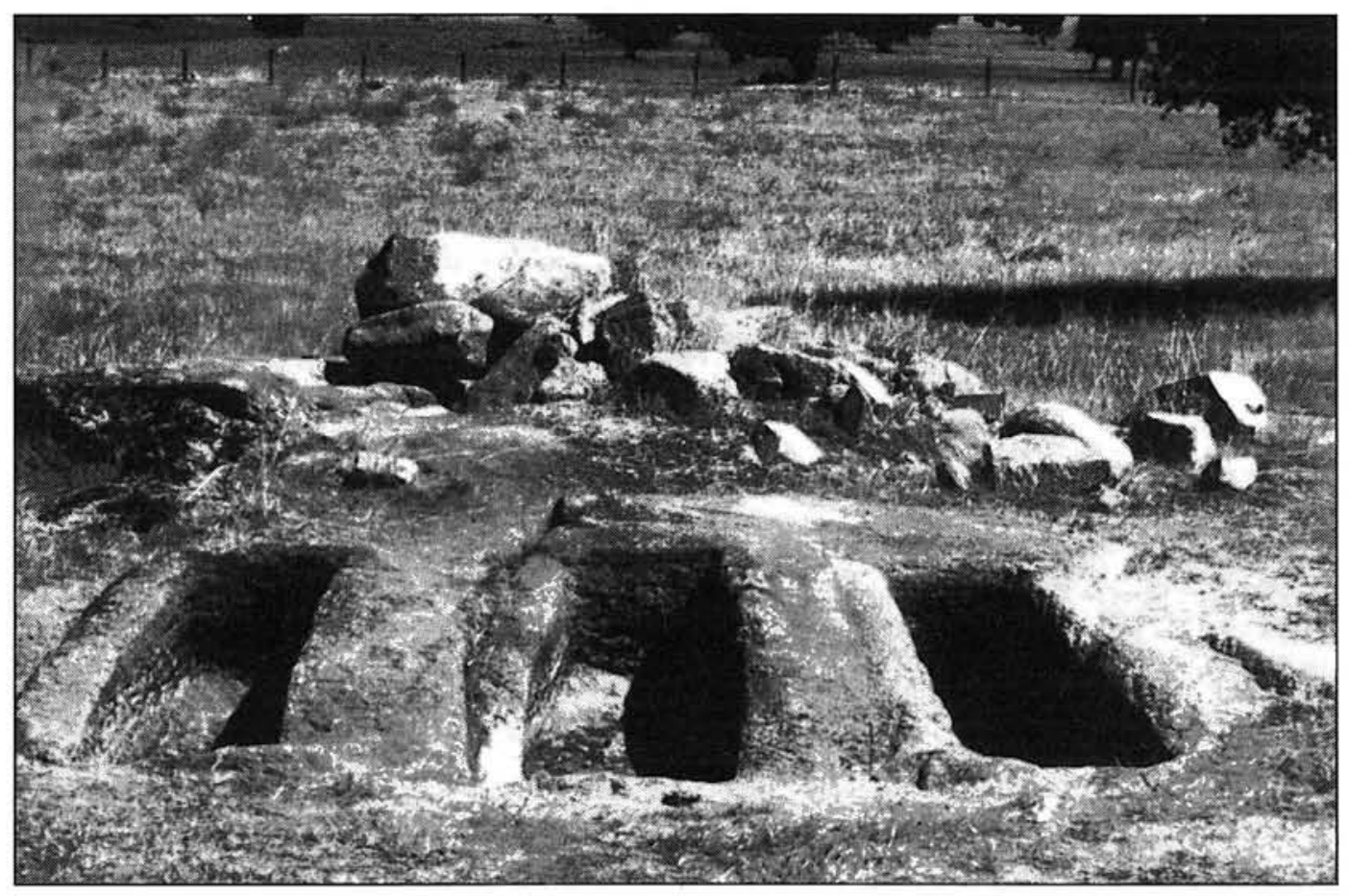

Lämina 6.-Tumbas antropoides

\section{CONSIDERACIONES FINALES}

Como resumen de todo lo hasta aquí dicho podríamos apuntar cómo las principales características de este sector de Sierra Morena son su medio físico desfavorable y una agricultura marginal provocada por varios factores entre los que podemos destacar su situación geográfica, la escasa aptitud del suelo para el cultivo y sus pautas climáticas. Todo ello ha provocado que la zona norte de la provincia de Córdoba deba entenderse en términos de economía marginal. La agricultura fue, fundamentalmente, de subsistencia dirigida al abastecimiento local, aunque es posible que debido a las características del medio físico la ganadería y la minería jugarían un papel de mayor importancia que la agricultura, llegando a abastecer a otras zonas de la provincia.

Su desarrollo histórico estuvo condicionado, fundamentalmente, por su situación periférica con respecto a los principales ejes de comunicación y por la escasa calidad y cantidad de recursos con que contaba $-\mathrm{y}$ cuenta- el medio físico.

Estos factores dieron lugar a una escasa intensidad de poblamiento, en general, si bien en determinados períodos se testimonia una mayor concentración en determinadas 
zonas más favorecidas. No obstante, la tónica general estuvo caracterizada por constantes variantes en el ritmo de ocupación en función de los diferentes condicionantes socioeconómicos que requerían unos recursos muy concretos, así como el control de determinadas vías de comunicación para poner en contacto Extremadura y Ciudad Real con el Valle del Guadalquivir, áreas económicamente más dinámicas con las que se relacionaron y de las que recibieron influencias, basculando hacia la Meseta en algunos momentos y hacia el valle del Guadalquivir en otros.

\section{BIBLIOGRAFIA}

ALMAGRO GORBEA, M. (1990): "El periodo orientalizante en Extremadura". La cultura tartésica y Extremadura. Cuadernos Emeritenses 2. Págs. 85-126. Mérida.

ARCE, J. (1982)· El último siglo de la España Romana: 284-409. Madrid.

BELÉN, M., EsCACENA, J. L., y BozziNo, M. I. (1992). "Las comunidades prerromanas de Andalucia Occidental" Paleoetnología de la Península Ibérica (Almagro-Gorbea, M. y Ruiz Zapatero. G. eds.) Complutum 2-3. Págs. 65-87.

Bendala GalAN, M. (1987). "Los Cartagineses en España" Historia General de España y America. Vol 1-3. Págs. 115-168. Madrid.

- (1989) "La génesis de la estructura urbana en la España Antigua" Cuadernos de Prehistoria y Arqueologia de la Universidad Autonoma de Madrid 16. Págs. 127-147

- (1992) "El mundo feniciopúnico y su expansión mediteránea" La Prehistoria de les illes de la Mediterrania Occidental (G. Roselló, ed.) Págs. 375-391 Palma de Mallorca.

BENDALA, M. et alij (1986): "Aproximación al urbanismo prerromano y a los fenómenos de transición y de potenciación tras la conquista" Los asentamientos ibéricos ante la romanización. Madrid. Págs. 121-140.

Bendana GalÁN, M., y CORZo SANCHEZ, R. (1992) "Etnografía de la Andalucía Occidental". Paleoetnología de la Península Ibérica (Almagro-Gorbea, M. y Ruiz Zapatero, G. Eds.). Complutum 2-3. Págs. 89-99.

BerRocal Rangel, L. (1992) Los pueblos célticos del suroeste de la Península Ibérica. Madrid.

- (1995) "La Beturia: Definición y caracterización de un territorio prerromano" Celtas y tûrdulos: la Beturia. (Velázquez. A. y Enriquez, J J. Eds.). Cuadernos Emeritenses 9. Págs. 151-204. Mérida.

BLÁZQUEZ, A. (1912): "Vías romanas de la Beturia de los Túrdulos". Boletín de la Real Academia de la Historia, Tomo LXI. Págs. 359-370.

BLAZQUEZ, J M. (1982-83): "Noticias sobre las excavaciones arqueológicas en la mina republicana de La Loba (Fuenteobejuna, Córdoba)" . Corduba Archaeologica, 12. Págs. 29-39. 
CAAMAÑo GeSTO, J. M. (1979): "Posible reutilización de caminos prerromanos en época romana". Gallaecia 3-4. Págs. 281-285.

CARR, K. E. (1992) Did Roman Goverment Matter? The standard of living in the Guadalquivir Valley, A.D. 300-700. Michigan.

CARRILlo DIAZ-PINES, J. R. (1991): "El poblamiento romano en las Subbéticas Cordobesas". Anales de Arqueologia Cordobesa 2. Págs. 225-252

CARrilo Dfaz-Pines, J. R., y Hidalgo Prieto, R. (1990) "Aproximación al estudio del poblamiento romano en la comarca de Palma del Rio (Cordoba): la implantación territorial", Ariadna 8. Págs. 38-68.

Celestino Pérez, S. (1991): "El yacimiento de Cancho Roano. Campañas 1986-1990". I Jornadas de Prehistoria y Arqueologia en Extremadura (1986-1990). Extremadura Arqueológica II. Págs. 185-197. Mérida.

CElestino PÉreZ, S., y Jiménez ÁVIA, F J. (1993): EI Palacio-Santuario de Cancho Roano IV. El sector norte. Badajoz.

CERRILLO MARTIN DE CÁCERES, E. (1995): " Los últimos romanos en Lusitania. Entre la tradición y el cambio". Los últimos romanos en Lusitania. Cuadernos Emeritenses 10. Pág. 11-48. Merida.

CORCHADO Y SORIANO, M. (1969): "Estudio sobre las vías romanas entre el Tajo y el Guadalquivir". Archivo Español de Arqueología 42. Págs. 124-158.

CORPUS INSCRIPTIONUM LATINARUM. (CIL II ${ }^{2}$ ). Pars VII.

CORTijo CEREzO, M. L. (1993) - La administración territorial de la Bética romana. Córdoba.

CORZO SÁNCHEZ, R. (1993) "Topografía y territorio de la Córdoba romana". Coloquio Internacional Colonia Patricia Corduba, una reflexión arqueológica (León P. eds.). Córdoba. Págs. 63-76.

CORZO, R., y JiMÉnEZ, A. (1980): "Organización territorial de la Bética". Archivo Español de Arqueología 53. Págs. 21-47.

CORzo, R., y TOSCANO, M. (1992): Las vías romanas de Andalucia. Sevilla.

DIAZ MARTínEZ, P. (1993): "El Imperio, los bárbaros y el control sobre la Bética en el siglo $\mathrm{V}^{n}$. Actas del I Coloquio de Historia Antigua de Andalucia. Tomo II. Córdoba. Págs. 317-325.

- (1995): "Propiedad y poder: la Iglesia Lusitana en el siglo VII" Los últimos romanos en Lusitania. Cuadernos Emeritenses 10. Pág. 49-72. Mérida.

DOMERGUE, C. (1967): "La mine antique de Diógenes". Melanges de la Casa de Velázquez. Págs. 46-47.

- (1971): "El cerro del plomo, mina El Centenillo (Jaén) " Noticiario Arqueologico Hispánico, $X V$.

- 1972): "Rapports ente le zone miniere de Sierra Morena et la plaine agricole du Gua. daiquivir à l'epoque romaine". Melanges de la Casa de Velázquez. 8. Madrid. 
- (1985) "Algunos aspectos de la explotación de las minas de la Hispania en la época republicana" Pyrenae 21. Págs. 91-95.

- 1987). Catalogue des mines et des fonderies antiques de la Peninsule Ibérique. 2 vois. Madrid.

- (1989): Les mines de la Peninsule Ibérique dans lantiquité romaine. Roma.

ENRfQueZ NAVASCUES, J. J. (1992): El Calcolítico o Edad del Cobre de la Cuenca Extremeña del Guadiana. Los poblados. Badajoz.

- 1995): "Los pueblos prerromanos de Extremadura" Celtas y Túrdulos: la Beturia. (Velázquez, A. y Enriquez, J. J. (eds.) Cuadernos Emeritenses 9. Págs. 49-76. Mérida.

FERNÁNDEZ JURADO, J. (1993). "Economía metalúrgica de Tartessos". Tartessos, 25, años después. Págs. 411-416. Jerez de la Frontera.

FERNÁNDEZ OCHOA, C., et alii. (1994): Sisapo I. Excavaciones arqueológicas en "La Bienvenida" Almodóvar del Campo (Ciudad Real). Toledo.

FERNÁNDEZ OCHOA, C., y ZARZAlEjos, M. (1995) "La estela de Chillón (Ciudad Real). Algunas consideraciones acerca de la funcionalidad de las "Estelas de guerrero" del Bronce Final y su reutilización en época romana" V Congreso Interncional de Estelas Funerarias. (C. De la Casa, ed.).Págs. 263-272.

Francisco MarTín. J. (1978). "Cuestiones en torno al limite occidental de la Bética" Actas del I Congreso de Historia de Andalucia. Diciembre de 1976. Vol.I. Córdoba.

GALÁN DOMinGo, E. (1993) Estelas, paisaje y territorio en el Bronce Final del Suroeste de la Peninsula lbérica. Madrid.

GARCiA-Bellido, M. P. (1993) "Sobre las dos supuestas ciudades de la Bética denominadas Arsa. Testimonios púnicos en la Beturia Túrdula" Anas IV. Págs. 81-92.

- (1995). "Célticos y púnicos en la Beturia según sus documentos monetales" Celtas y túrdulos: la Beturia. (Velázquez A. y Enríquez J.J. Eds.) Cuadernos Emeritenses 9. Págs. 255-292. Mérida.

GARClA IGLESIAS, L. (1971) - "La Beturia un problema geográfico de la Hispania Antigua" Archivo Español de Arqueologia 44. Págs. 86-108.

Garcia Moreno, L. A. (1989)- "Túrdulos, turdetanos y tartessios. Una hipótesis" Gerion, Anejos II. Págs. 289-294.

GARCIA Romero, J. (1993): "El aprovechamiento minero de la comarca de Los Pedroches durante la época romana. Area cronológica: república y alto imperio. Área temática: economia". Actas del I Coloquio de Historia Antigua de Andalucía. Págs. 97-102.

GAVILAN CEBALLOS, B. (1985): " Excavación arqueológica de urgencia en el yacimiento de Sierra Palacios (Belmez, Córdoba) 1985". N.A.A. Págs. 102-104.

- (1986a): "Excavaciones en Sierra Palacios (Belmez, Córdoba)". Revista de Arqueología 61. Págs. 29-32.

- (1986b): "Excavación arqueológica de urgencia en el dólmen de Casas de Don Pedro". Anuario Arqueologico de Andalucia 1986, Sevilla, Vol. III. Págs. 118-120. 
Gavilán Ceballos, B., y Vera Rodríguez, C. (1989-90) "La Edad del Cobre en el Alto Valie del Guadiato (tramo Fuente Obejuna-Belmez, Córdoba) Características de los asentamientos y evolución diacrónica" Cuadernos de Prehistoria de la Universidad de Granada. 14-15. Págs. 13.

IGLESIAS GIL, J. M. (1977): "Datos en tomo a Baedro" Hispania Antiqua VII. Págs. 157-163

- (1978) "Nuevas aportaciones epigráficas del Valle de Los Pedroches". Zephyrus 2829. Págs. 337-342.

- (1993) "Los límites del ager mellariensis y del ager baedronensis. Actas del I Coloquio de Historia Antigua de Andalucia. Córdoba 1988. Vol I. Págs. 491-494. Córdoba.

- (1996) "A propósito del territorio del Ager Mellariensis y del Ager Baedronensis en los límites de la Beturia de los Túrdulos" Anales de Arqueología Cordobesa 7. Págs. $163-180$

KNAPP, R.C. (1977). Aspects of the Roman Experience in Iberia, 206-100b.C. Anejos de Hispania Antiqua IX. Vitoria.

López ONTIVERos, A. (Ed.) (i985) Córdoba y su provincia. Tomo I. Sevilla.

lopez Ontiveros, A., y Valle Buenestado, B. (1993) "Geografia" Córdoba capital. Vol. III. Córdoba.

MALUUQUER DE MOTES, J. (1985) La civilización de Tartessos. Biblioteca de la Cultura Andaluza, Historia. Sevilla.

- (1986) "Comercio continental focense en la Extremadura Central" Ceramiques gregues i helenistiques a la Peninsula Iberica. Págs. 19-25.

Marcos Pous, A., y Vicent ZaragozA, A. M. (1983) "Excavaciones en la Ermita de Nuestra Señora de Tres Cruces" Novedades de Arqueologia Cordobesa. Exposición Bellas Artes. Págs. 29-33. Córdoba.

MARTIN DE LA CRUZ, J.C. (1994) "Los primeros contactos entre Grecia y la Península Ibérica. La problemática planteada por los hallazgos de Montoro (Córdoba)" Arqueologia de la Magna Grecia, Sicilia y Peninsula Ibérica. (Vaquerizo Gil, D. Coord.) Págs. 111-143. Córdoba.

MELCHOR Gil, E. (1993) "Vías romanas y explotación de los recursos mineros de la zona norte del Conventus Cordubensis". Anales de Arqueología Cordobesa. 4. Págs. $63-$ 90.

- (1995): Vias romanas de la provincia de Córdoba. Córdoba.

MOPU (1993) El Camino de Andalucia. Itinerarios históricos entre la Meseta y el Valle del Guadalquivir. Madrid.

MURILLo REDONDO, J. F. (1986a) Eneolítico y Edad del Bronce en el Norte de la provincia de Córdoba, 2 vols. Memoria de Licenciatura (inédita), Universidad de Córdoba.

- (1986b) "Nuevos yacimientos Calcolíticos en el sector noroccidental de la provincia de Córdoba". Estudios de Prehistoria Cordobesa 1. Págs. 77-94. 
- (1993): "Poblamiento protohistórico y minería en el Norte de la Provincia de Córdoba". Actas del I Coloquio de Historia Antigua de Andalucía (Córdoba 1988). Págs. 265-282.

- (1994a): La cultura tartésica en el Guadalquivir Medio. Ariadna 13-14.

- (1994b): "Griegos e Indigenas en la Península Ibérica. Testimonios materiales". Arqueologia de la Magna Grecia, Sicilia y Peninsula Ibérica. (Vaquerizo Gil, D. Coord.). Págs. 147-187 Córdoba.

- (1994c): "La estela de la Ribera Alta (Córdoba): Consideraciones en torno a las estelas decoradas con escudo, espada y lanza" Anales de Arqueología Cordobesa 5. Págs. 11-32.

- (e.p.)' "Aproximación al poblamiento Calcolítico en el norte de la provincia de Córdoba" XXI Congreso Nacional de Arqueología.

Murillo Redondo, J.; Quesada SANZ, F., VAQuerizo GIL, D.; CARRLlo DIAZ-PINES, J. R., y MORENA LOPEZ, J. A. (1989) "Aproximación al estudio del poblamiento protohistórico en el Sureste de Córdoba: unidades políticas, control del territorio y fronteras". Arqueología Espacial Fronteras. Vol. 13. Págs. 151-172.

NierhauS, R. (1964): "Baedro" Madrider Mitteilungen 5. Págs. 205-219.

OCAÑA TORREJÓN, J. (1970)- "Caminos viejos de Los Pedroches". ". Boletín de la Real Academia de Córdoba Págs. 71-90.

OCAÑA TORREjON, J., y RODRIGUEZ ADRADOS, A. (1962) "El yacimiento de Majada de la Iglesia Virgen de las Cruces". Historia de la villa de Pedroche y su comarca. Córdoba.

OREJAS SACO DEL VALLE, A. (1996) Estructura social y territorio. El impacto romano en la cuenca noroccidental del Duero. Madrid.

PADIlla MONGE, A. (1989)- La provincia romana de la Betica (253-422). Ecija.

RAMíREZ y de LAS CASAS DEZA, M. M. a . (1986): Corografia Histórico-Estadística de la Provincia y Obispado de Córdoba. (Ed. de A. Lopez Ontiveros; original de 1867). Córdoba.

RODŔGuEZ DIAZ, A. (1993)' "Sobre la periferia turdetana y la configuración diversa de la Beturia prerromana. Célticos y túrdulos en el Guadiana Medio" Spal2. Págs. 243-267.

- (1994): "El Valle Medio del Guadiana, "Espacio de Frontera" en la Protohistoria del Suroeste (I)". Saguntum 27. Págs. 107-124.

- (1995a): "Territorio y etnias prerromanas en el Guadiana Medio: Aproximación arqueológica a la Beturia Túrdula". Celtas y túrdulos: la Beturia. (Velázquez, A. y Enríquez, J.J Eds.). Cuadernos Emeritenses 9. Págs. 205-254. Merida.

- (1995b): "El Valle Medio del Guadiana, "Espacio de Frontera" en la Protohistoria del Suroeste (II)". Saguntum 28. Págs. 111-130.

RODRíguez DíaZ, A., y ENRIQuEZ NAVASCuÉs, J. J. (1992) · "Las Necrópolis protohistóricas en Extremadura". Congreso de Arqueología Ibérica. Las Necropolis (Blánquez, J. y Antona, V. Coord.). Serie Varia 1. Págs.531-562. Madrid. 
RODRfGUEZ NeILA, J. F. (1988): Del amanecer prehistórico al ocaso visigodo.Historia de Córdoba 1. Córdoba.

ROLDÁN HERVAS, J. M. (1975): Itineraria Hispana. Fuentes antiguas para el estudio de las vías romanas en la Peninsula Ibérica. Anejo de Hispania Antigua.

- 1993). "Los comienzos de la romanización de Andalucia: la organización territorial de la Ulterior en el siglo II a.C". Actas del I Coloquio de Historia Antigua de Andalucia. Tomo I. Págs. 319-330.

ROMERO CORRAi, R. M. a. (1995): "La presa romana de Torretejada (Belalcázar, Córdoba)" Anales de Arqueologia Cordobesa 5. Págs. 295-309.

- (1996): Análisis diacrónico del poblamiento en el Norte de la provincia de Córdoba. Memoria de Licenciatura inédita.U.A.M.

RUIZ-GÁLVEZ, M., y GALAN, E. (1991): "Las estelas del suroeste como hitos de vías ganaderas y rutas comerciales" Trabajos de Prehistoria 48. Págs. 257-273.

RUIZ RODRIGueZ, A. (1998): "Los Iberos y su espacio". Los Iberos. Principes de Occidente. Págs. 77-89.Barcelona

SAlVADOR VenTURA, F (1990): Hispania meridional entre Roma y el Islam. Economía y sociedad. Granada.

SiliterS, P. (1990): Les voies de communication dans I'Hispanie Meridionale. Paris.

STYLOW, A. U. (1985): "Ordenación territorial romana en el Valle de Los Pedroches (Conventus Cordubensis)" XVII Congreso de Arqueología Nacional Págs. 657-665.

- (1991): "El Municipium Flavium $V(-$ ) de Azuaga (Badajoz) y la municipalización de la Baeturia Turdulorum". Studia Historica IX. Págs. 11-27.

TOVAR, A. (1974-1976): Iberische Landeskunde. Baetica. Baden-Baden.

UBIÑA, J.F. (1981): La crisis del siglo III en la Bética. Granada.

ULBERT, T. (1968): "El Germo, Kirche und Profanbau aus dem frühen 7. Jahrhundert mit Tafel 121-151 und 34 Textabbildungen". Madrider Mitteilungen 9. Págs. 329-398.

VAQUERIZO Gil, D.; MurILlo REDONDO, J., y QueSADA SANZ, F (1991): "Avance de la prospección arqueológica de la Subbética cordobesa: la Depresión Priego-Alcaudete" Anales de Arqueología Cordobesa 2. Págs. 117-170.

VAQuerizo, D., et aliI (1994): El Valle Alto del Guadiato (Fuenteobejuna, Córdoba). Córdoba

VENTURA VILLANUEVA, A. (1993): "Susum ad montes s(ocietatis) s(isaponensis): nueva inscripción tardorrepublicana de Corduba" Anales de Arqueología Cordobesa 4. Págs. $49-61$.

VERA RODRígueZ, J. C. (1996) "Consideraciones en torno a los recipientes ibéricos con soporte de manos: el hallazgo de Hinojosa del Duque (Córdoba)" Anales de Arqueologia Cordobesa 7. Pág. 235-250

ZARZAiEjOS, M., et alii. (1994): "Excavaciones en La Bienvenida (Ciudad Real). Hacia una definición preliminar del horizonte histórico-arqueológico de la Sisapo antigua." 
Jornadas de Arqueología de Ciudad Real en la Universidad Autónoma de Madrid. Pág. 167-194.

ZarZalejos, M. (1995): Arqueología de la región Sisaponense. Aproximación a la evolución histórica del área SW de la provincia de Ciudad Real (fines del siglo vIII a.C.sigio II d.C.).Tesis Doctoral UAM. 